$(\mathbb{8} 86) .{ }^{146}$ Für die zuvor so umstrittenen Bereiche der Hilfe zur Erziehung und die Ausbildungshilfe enthielt der Entwurf für erstere nur eine Übergangsbestimmung bis zum Inkrafttreten des Jugendhilfegesetzes. ${ }^{147}$ Die Ausbildungshilfe blieb weiterhin eine Hilfe in besonderen Lebenslagen, ohne daß damit eine entsprechende Hilfe auch im geplanten JHG ausgeschlossen gewesen wäre, da das BSHG stets anderen Gesetzen gegenüber nachrangig blieb und hier als „eine Art ,Ausfallbürgschaft" “ fungierte. ${ }^{148}$

Noch in einer weiteren Hinsicht war der Entwurf, ohne daß sich hier sein Wortlaut auch nur mit einer Silbe geändert hätte, modifiziert worden: Am 2. Dezember 1959 hatte das Bundesverfassungsgericht geurteilt, daß Soll-Vorschriften für die Verwaltung prinzipiell ebenso verbindlich seien wie Muß-Vorschriften, zumindest solange die Verwaltung nicht besondere Umstände darlegen und beweisen könne, die ein Abweichen von der Regel zuließen. ${ }^{149}$ Die Entscheidung hierüber blieb freilich eine Ermessensentscheidung des Sozialhilfeträgers. ${ }^{150} \mathrm{Am}$ 22. Februar 1960 wurde der Regierungsentwurf des BSHG an den Bundesrat übersandt. ${ }^{151}$

\title{
2. Der Regierungsentwurf im Bundesrat und im Bundestagsausschuß für Kommunalpolitik und öffentliche Fürsorge
}

Im Bundesrat verfügte die CDU/CSU bis zu den Landtagswahlen in BadenWürttemberg im Mai 1960 über eine knappe relative Mehrheit von 18 sicheren der insgesamt 41 Bundesratsstimmen (ohne die vier beratenden Stimmen Berlins): Diese stammten aus den unionsregierten Ländern Nordrhein-Westfalen, Bayern, Schleswig-Holstein und Rheinland-Pfalz; die 15 Stimmen für die SPD stellten die

$146 \$ 86$, ebenda, bestimmte:

\section{$\int 86$ \\ „Einrichtungen}

(1) Die Träger der Sozialhilfe sollen darauf hinwirken, daß die zur Gewährung der Sozialhilfe geeigneten Einrichtungen ausreichend zur Verfügung stehen. Sie sollen eigene Einrichtungen nicht neu schaffen, soweit geeignete Einrichtungen anderer Träger, vor allem der freien Wohlfahrtspflege, vorhanden sind, ausgebaut oder geschaffen werden können.

(2) Werden im Einzelfall Einrichtungen anderer Träger in Anspruch genommen, sind Vereinbarungen über die von den Trägern der Sozialhilfe zu erstattenden Kosten anzustreben, soweit darüber keine landesrechtlichen Vorschriften bestehen.

(3) Die Bundesregierung kann im Falle des Absatzes 2 durch Rechtsverordnung mit Zustimmung des Bundesrates bestimmen, welche Kostenbestandteile bei den zu erstattenden Kosten zu berücksichtigen sind.“

$147 \mathrm{Vgl}$. $\int 145$ Abs. 3, ebenda.

148 Vgl. $\int \$$ 29ff., ebenda; Zitat: Muthesius, in: NDV 40 (1960), S. 178.

149 Vgl. Deutsches Verwaltungsblatt 1960, S. 252.

150 Vgl. Gottschick, Bundessozialhilfegesetz, 1962, S. 86.

151 Vgl. Bundesjustizminister Fritz Schäffer für den Bundeskanzler an den Präsidenten des Bundesrates, 22.2.1960, BR 1960, Drs. 53/60. 
Länder Niedersachsen, Hessen, Hamburg und Bremen. Ebenfalls für die CDU verbucht wurden in der Regel das Saarland (3 Stimmen) und Baden-Württemberg (5 Stimmen), denn dort regierten Ministerpräsidenten der CDU, allerdings in Koalition mit der SPD. Sowohl diese parteipolitischen Konstellationen, ebenso das gerade für den Fürsorgebereich typische Auseinanderfallen von Gesetzgebungskompetenz und Finanz- und Verwaltungsverantwortung und nicht zuletzt die konfessionspolitische Komponente bargen für den BSHG-Regierungsentwurf im Bundesrat eine Reihe von Unwägbarkeiten. Wie gesehen, hoffte die Sozialabteilung in der Subsidiaritätsfrage sogar darauf.

Erst recht bauten die Kommunen auf Korrekturen durch die Länder und setzten den Hebel beim federführenden Innenausschuß des Bundesrates an - wie es zunächst schien, mit Erfolg. Die Zeit drängte, denn der Bundesrat hatte nach Art.76 Abs. 2 GG nur drei Wochen Zeit für eine Stellungnahme. Bereits einen Tag nach Verabschiedung des Entwurfs im Bundeskabinett beauftragte der DST-Sozialausschuß seinen Arbeitskreis „Fürsorgerecht“, kurzfristig eine vorläufige Stellungnahme für den Bundesrat zu erarbeiten. ${ }^{152}$ Wie zu erwarten, protestierten die städtischen Fürsorgeexperten vor allem gegen die Bestimmungen zugunsten der freien Wohlfahrtspflege: Sie plädierten dafür, die Förderungsverpflichtung für die Sozialhilfeträger in $\$ 10$ Abs. 3 Satz 2 zu streichen, da sie gegen den Grundsatz der finanziellen Verantwortlichkeit der Kommunen verstoße und zwangsläufig zu einer Kontrolle der freien Verbände führen müsse. Bisher leisteten die Kommunen „auf freiwilliger Basis erhebliche finanzielle Hilfen und materielle Unterstützungen" ${ }^{153}$, und zwar meist ohne Zweckbindung und damit verbundene Beaufsichtigung. Daneben stießen sich die Kommunalvertreter vor allem an dem Vorbehalt zugunsten von Einrichtungen der freien Wohlfahrtspflege und forderten ebenfalls dessen Streichung; $\mathbb{\int} 86$ Abs. 1 Satz 2 des Regierungsentwurfs schränke die Betätigungsfreiheit der Sozialhilfeträger „in nicht zumutbarer Form ein“. Er widerspreche ihrer gesetzlichen Verantwortung für die Erfüllung der Sozialhilfeaufgaben, dem Grundsatz der partnerschaftlichen Zusammenarbeit zwischen öffentlichen und freien Trägern sowie der Wahlfreiheit des Hilfesuchenden: „Der Regierungsentwurf läßt außer Acht, daß die Einrichtungen der freien Träger, entsprechen[d] ihrer religiösen oder weltanschaulichen Grundhaltung, nur Teile der Bevölkerung ansprechen, während andere Personenkreise es vorziehen, die Einrichtung des ,neutralen' öffentlichen Sozialhilfeträgers in Anspruch zu nehmen." Das gleiche gelte für den Vorrang der freien Träger bei der Beratung ( $\$ 8$ Abs.2). Auch die Streichung der Gewährleistung der gewünschten geistlichen Betreuung bei Anstaltsunterbringung ( $\int 3$ Abs. 3) wurde gefordert, da sonst bei religiösen Minderheiten u.U. eine Betreuung unmöglich würde. Daneben forderte der DST u.a., die Kommunen an der Festsetzung der Regelsätze zu beteiligen und die wirtschaftliche Hilfe für Jugendliche wieder in das Gesetz aufzunehmen, und wiederholte

152 Vgl. die Niederschriften der Sitzungen des DST-Sozialausschusses am 18./19.2.1960 (Auszug) und des Arbeitskreises „Fürsorgerecht“ am 23.2.1960, LAB, B Rep. 142-9, 1284.

153 Vgl., auch für das Folgende, Vorläufige Stellungnahme des DST zum BSHG-Regierungsentwurf vom 2.3.1960, ebenda. 
seine grundsätzlichen Bedenken gegen die „versorgungsähnliche“ Leistung der Blindenhilfe. ${ }^{154}$

Um den kommunalen Bedenken mehr Gewicht zu verleihen, wollten die Spitzenverbände dem Innenausschuß des Bundesrates zu dessen Sitzung am 11. März eine gemeinsame Stellungnahme ihrer Bundesvereinigung vorlegen.155 Als Oel jedoch erfuhr, daß der Innenausschuß einen Unterausschuß „Bundessozialhilfegesetz" eingesetzt hatte, der bereits am 2. März zusammentreten sollte, ließ er ihm nach Rücksprache mit den anderen Spitzenverbänden die vom Arbeitskreis erarbeitete Stellungnahme per Eilboten in die Sitzung bringen. ${ }^{156}$ Dem Unterausschuß gehörten im wesentlichen die Fürsorgereferenten der Länder an, die auch bisher schon an der Beratung des Gesetzentwurfs beteiligt gewesen waren. Insofern war ihrem alten Anliegen, im Bundesrat Fürsorgefragen durch die zuständigen Experten zu beraten, doch noch Genüge getan. Dies war aus Sicht der Fürsorgespezialisten umso wichtiger, als schon aufgrund der kurzen Beratungsfrist der Vorarbeit in den Ausschüssen große Bedeutung zukam, wenn auch die Abstimmung im Plenum dann aufgrund der Beschlußlage in den jeweiligen Landeskabinetten erfolgte. Im Unterausschuß wie im Innenausschuß selbst waren die Stimmen nicht nach Ländergröße gewichtet, sondern ihrer beratenden Funktion entsprechend hatte jedes Land eine Stimme, so daß sich auch die parteipolitischen Proportionen veränderten: Vier Stimmen von unionsregierten Ländern standen vier sozialdemokratische Stimmen gegenüber; dazu zwei Stimmen der Länder mit einer von der CDU geführten Großen Koalition sowie die Stimme des hier ebenfalls abstimmungsberechtigten Berlin mit seiner SPD-geführten Großen Koalition. Wie sich zeigen sollte, spielten auf der Ebene der Fürsorgereferenten die parteipolitischen ebenso wie die konfessionellen Aspekte ohnehin nur eine begrenzte Rolle; hier dominierten - wie auch sonst in den Bundesratsausschüssen ${ }^{157}$ - die Verwaltungsgesichtspunkte.

Auf der Sitzung am 2./3. März, bei der auch zahlreiche Beamte der Bundesministerien zugegen waren, exponierte sich der Vertreter des CDU-regierten und überwiegend katholischen Rheinland-Pfalz, der politischen Heimat von Familienminister Wuermeling, zugunsten der Anliegen des Katholischen Büros; sein Gegenspieler war der Vertreter des sozialdemokratisch regierten und protestantisch geprägten Niedersachsen, der in der Subsidiaritätsfrage den kommunalen Standpunkt verteidigte und darin unter anderem von den Vertretern der Länder Schleswig-Holstein, Bayern und insbesondere Baden-Württemberg, das ja immerhin die Zentralen beider christlicher Wohlfahrtsverbände in Stuttgart und Freiburg beheimatete, unterstützt wurde. ${ }^{158}$

\footnotetext{
154 Ebenda.

155 Vgl. Vermerk Kelm vom 12.1.1960, LAB, B Rep. 142-9, 1284.

156 Vgl. Oel an Ministerialrat Müller, Bundesrat, 2.3.1960; Oel an DLT/DGT/DGB, 2.3. 1960; Vermerk L[ehmann]-G[rube], 4.3.1960, ebenda. Die offizielle vorläufige Stellungnahme der Bundesvereinigung der Kommunalen Spitzenverbände vom 5.3.1960, eben$\mathrm{da}$, für die beteiligten Bundesratsausschüsse entsprach derjenigen des Arbeitskreises bis auf geringe Abweichungen.

$157 \mathrm{Vgl}$. Ellwein, Entscheidungsprozeß, S. 229f.

158 Vgl. Niederschrift über die Sitzung des Unterausschusses „Bundessozialhilfegesetz“ des Ausschusses für Innere Angelegenheiten am 2./3.3.1960, BAK, B 106/20653a.
} 
Das niedersächsische Sozialministerium hatte unter Staatssekretär Auerbach zur Stellung der freien Verbände einen Antrag vorbereitet, der inhaltlich und argumentativ weitgehend den Forderungen der kommunalen Spitzenverbände entsprach. ${ }^{159}$ Ein Vertreter Niedersachsens berief sich im Ausschuß auch auf die niedersächsischen Landesverbände der freien Wohlfahrtspflege, die mit Ausnahme der Caritas Einverständnis signalisiert hätten. ${ }^{160}$ Tatsächlich war die Haltung des Landesgeschäftsführers der Inneren Mission, Götz Maltusch, auf einer Besprechung im niedersächsischen Sozialministerium eher unklar gewesen, keineswegs jedoch eindeutig im Sinne Auerbachs. ${ }^{161}$ Im Unterausschuß jedenfalls wurde der Antrag Niedersachsens von einer klaren Mehrheit angenommen, dagegen stimmten nur die Vertreter der überwiegend katholischen Länder NordrheinWestfalen, Rheinland-Pfalz und Saarland. Einzig die Streichung von $\ 3$ Abs. 3 konnte Niedersachsen nicht durchsetzen, doch wurde diese Bestimmung auf Antrag Bayerns wieder etwas abgeschwächt. ${ }^{162}$

Von den weiteren Änderungsvorschlägen des Unterausschusses waren vor allem diejenigen zu den Einkommensgrenzen wichtig: Anders als in ihren Gesprächen mit Gottschick im Herbst 1958 forderten die Ländervertreter jetzt eine Erhöhung der allgemeinen Einkommensgrenze auf den zweifachen Regelsatz (plus Beibehaltung des Familienzuschlags von 60 DM je Angehörigen), denn, so die Begründung lapidar, ein „Grundbetrag in Höhe des Eineinhalbfachen des Regelsatzes eines Haushaltsvorstands reicht nicht aus“. ${ }^{163}$ Im Bundesdurchschnitt bedeutete das für eine vierköpfige Familie eine Erhöhung des Grenzbetrags von 335 DM auf 371 DM. ${ }^{164}$ Die erhöhte allgemeine Einkommensgrenze (Familienzuschlag 80 DM) sollte wegen ihrer „besonderen Bedeutung“ auch für die Ausbildungshilfe, die Hilfe zur Pflege und die Familien- und Hauspflege gelten. Wie schon auf der Wohlfahrtsministerkonferenz vom Mai 1959 wurde außerdem eine weitere Einschränkung der Kostenersatzpflicht sowie die Wiederaufnahme der „Hilfe für junge Menschen“ gefordert, da nicht abzusehen sei, wann ein Bundesjugendhilfegesetz in Kraft trete. Neben gewissen Verbesserungen bei der Ausbildungs- und der Eingliederungshilfe sowie der Möglichkeit der Freiheitsentziehung bei der Gefährdetenhilfe empfahl der Unterausschuß mit knapper Mehrheit auch die Streichung der Bestimmung über die Fachkräfte als unzulässigen Eingriff in die Verwaltungshoheit der Länder.

Die Empfehlungen des Unterausschusses deckten sich so weitgehend mit den Änderungswünschen der kommunalen Spitzenverbände, daß diese auf eine Anhörung vor dem Bundesratsausschuß für Innere Angelegenheiten verzichteten. ${ }^{165}$

159 Vgl. ebenda; ferner die Veröffentlichung des niedersächsischen Fürsorgereferenten Willi Hoppe, Verhältnis.

160 Vgl. Vermerk Ranke vom 8.3.1960, ADW, HGSt, SP-S XXV 1: 100-1/2.

161 Vgl. Collmer an Ranke, 11.3.1960, ADW, HGSt, SP-S XXV 1: 422-1/1.

162 Vgl. Niederschrift über die Sitzung des Unterausschusses „Bundessozialhilfegesetz“ am 2./3.3.1960, BAK, B 106/20653a.

$163 \mathrm{Vgl}$. ebenda.

164 Vgl. Gottschick, Entwurf, S. 143.

165 Vgl. die zwischen dem niedersächsischen Sozialministerium und dem DST am 7.3.1960 gewechselten Fernschreiben, LAB, B Rep. 142-9, 1284. 
Tatsächlich übernahm der Innenausschuß am 11. März die Empfehlungen fast ohne Ausnahme: Dazu zählte neben der nun doch aufgenommenen Verpflichtung, im Rahmen der Hilfe zum Lebensunterhalt den besonderen Bedarf von Kindern und Jugendlichen zu berücksichtigen, die Erhöhung der Einkommensgrenze für die Blindenhilfe auf 1000 DM. ${ }^{166}$ Im Innenausschuß allerdings hatte sich nun auch der Vertreter Bayerns auf die katholische Seite geschlagen und vergeblich - gegen die Änderungen bei den Regelungen zur Subsidiaritätsfrage gestimmt. 167

Um den Erfolg im Innenausschuß zu sichern und zu verhindern, daß die unionsgeführten und mehr oder weniger protestantisch geprägten Länder Schleswig-Holstein und Baden-Württemberg auf Druck aus Bonn hin im Plenum des Bundesrates ebenfalls ihre Haltung zur Subsidiaritätsfrage noch änderten, drängte Auerbach noch am gleichen Tag seine Kontaktleute Collmer und Maltusch, die dortigen Ministerpräsidenten und zuständigen Minister von evangelischer Seite entsprechend zu beeinflussen. ${ }^{168}$ Genau das Gegenteil schlug ebenfalls am 11.März Caritas-Präsident Stehlin vor: Die Spitzenvertreter der beiden christlichen Wohlfahrtsverbände sollten bei Kiesinger anrufen, um „ihn auf die Wichtigkeit der Aufrechterhaltung der Vorlage der Bundesregierung hinzuweisen und ihn zu bitten, in entsprechender Weise einen Beschluss im Kabinett Baden/Württemberg herbeizuführen". ${ }^{169}$ In dieser Situation wurde deutlicher denn je, daß auch bei den unmittelbar Beteiligten auf evangelischer Seite die Subsidiaritätsfrage sehr unterschiedlich eingeschätzt wurde: Die eher wohlfahrtspolitisch orientierten Vertreter der Diakonie, auch der CDU-nahe Collmer, bewerteten $\mathbb{1 0}$ des Regierungsentwurfs kritisch und wollten sich für diese Regelung nicht offiziell einsetzen. ${ }^{170}$ Umgekehrt waren sie auch nicht bereit, öffentlich „gegen den Caritasverband, mit dem wir viel zusammenarbeiten, Schützenhilfe für die von der Arbeiterwohlfahrt beeinflussten Regierungen zu gewähren“. ${ }^{171}$ Dies umso weniger, als sie auch der Konzeption Auerbachs nicht zustimmten. ${ }^{172}$ Die ganze Diskussion, so Collmer intern im März 1960, sei „deshalb so unerfreulich, weil sowohl die katholische wie die sozialistische Seite ihr Gesellschaftsverständnis für das Sozialhilfegesetz als Norm ansieht. Dabei kann es nach dem Grundgesetz im heutigen Staat nur darum gehen, dass [...] jeder Gruppe eine entsprechende Entfaltungsund Gestaltungsmöglichkeit gegeben wird““.173 $\mathrm{Da}$ die kommunale Verwaltung

166 Vgl. Empfehlungen des federführenden Ausschusses für Innere Angelegenheiten, des Ausschusses für Arbeit und Sozialpolitik, des Finanzausschusses, des Rechtsausschusses vom 11.3.1960, BR 1960 Drucksachen, Drs. 53/1/60.

167 Vgl. Auerbach an Collmer, 11.3.1960, ADW, HGSt, SP-S XXV 1: 426-1/1.

168 Vgl. ebenda; Maltusch an Ranke, 15.3.1960, ADW, HGSt, SP-S XXV 1: 103-1/1.

169 Vermerk Collmer vom 11.3.1960, ADW, HGSt, SP-S XXV 1: 100-1/2.

170 Vgl. Vermerk Ranke vom 8.3.1960, ebenda; Maltusch an Ranke, 15.3.1960, ADW, HGSt, SP-S XXV 1: 103-1/1; Heun an Bonner Verbindungsstelle von Innerer Mission/Hilfswerk, 4.4.1960, ADW, HGSt, SP-S XXV 1: 102-1/1.

171 Maltusch an Ranke, 15.3.1960, ADW, HGSt, SP-S XXV 1: 103-1/1.

172 Vgl. Collmer an Auerbach, 15.3.1960, ADW, HGSt, SP-S XXV 1: 426-1/1, sowie eine vertrauliche Stellungnahme von Maltusch zu den $\$ \mathbb{S} 10,86$ des Regierungsentwurfs, Anlage zu Maltusch an Collmer, 15.3.1960, ADW, HGSt, SP-S XXV 1: 103-1/1.

173 Collmer an Maltusch, 21.3.1960, ADW, HGSt, SP-S XXV 1: 103-1/1. 
noch immer zur „Untertanenbehandlung“ neige, müßten sich die freien Verbände vor allem in ihrem Arbeitsstil davon unterscheiden; damit werde „keine Vorrangigkeit der Verbände vertreten, wohl aber die Wahrnehmung einer ihnen gemäßen Verpflichtung, die sie besser erfüllen können [...] als die kommunalen Verwaltungen". 174

Die primär kirchenpolitisch agierende Bonner Kirchenkanzlei unter dem unionsnahen EKD-Bevollmächtigten Kunst hingegen unterstützte die katholische Linie mittlerweile eindeutig. Der Ausweg aus dem Dilemma bestand schließlich darin, daß Bischof Kunst persönlich bei Kiesinger und von Hassel um Unterstützung für den Regierungsentwurf warb, Collmer vertraulich gegenüber Auerbach seine Kritik deutlich formulierte und seinen Osterurlaub antrat, und Maltusch, der es weder mit dem niedersächsischen Sozialministerium noch der niedersächsischen Caritas verderben wollte, einen zurückhaltenden Brief an den schleswigholsteinischen Kultusminister und Kirchenrat Edo Osterloh schrieb. ${ }^{175}$

Die kirchlichen Interventionen in Kiel und Stuttgart zeigten Wirkung: Schleswig-Holstein distanzierte sich von den Empfehlungen des Innenausschusses des Bundesrats, indem es für die Beratung des Plenums den Antrag stellte, nur mehr $\$ 10$ Abs. 4 des Regierungsentwurfs zu streichen. ${ }^{176}$ Ministerpräsident Kiesinger, der ja immerhin ein Jahr zuvor den katholischen Freiburger Bischof in dieser Frage unterstützt hatte, teilte am 16. März, zwei Tage vor der Bundesratssitzung, dem Bundesinnenminister mit, seine Regierung sei unter einer Bedingung zur Zustimmung zu den Subsidiaritätsbestimmungen bereit: $\mathrm{Daß}$ die Bundesregierung erkläre, $\mathbb{S} 86$ sei so zu verstehen, daß die öffentlichen Träger zurückstehen sollten, „wenn geeignete Einrichtungen anderer Träger, vor allem der freien Wohlfahrtspflege, vorhanden sind, ausgebaut oder überwiegend aus eigener Kraft geschaffen werden können“. ${ }^{177}$ Tatsächlich gab Staatssekretär Anders bei der Beratung des Regierungsentwurfs im Bundesrat am 18. März eine entsprechende Erklärung ab. ${ }^{178}$ Daraufhin passierten mit den entscheidenden Stimmen Baden-Württembergs und Schleswig-Holsteins die $\mathbb{\$} \mathbb{8}, 10$ und 86 des Regierungsentwurfs doch den Bundesrat; auf Antrag von Rheinland-Pfalz wurden sie sogar im Sinne des Katholischen Büros noch etwas modifiziert. ${ }^{179}$ Die Hoffnungen Duntzes und der kommunalen Spitzenverbände, bereits der Bundesrat werde diese Regelungen in ihrem Sinne „korrigieren“, hatten sich nicht erfüllt.

174 Ebenda; ähnlich Collmer, Hilfe, S. 88ff.

175 Vgl. Collmer an Ranke, 11.3.1960; Kunst an Kiesinger, 12.3.1960, Abschrift; Arnade an Heun, 12.3.1960, ADW, HGSt, SP-S XXV 1: 422-1/1; Maltusch an Osterloh, 15.3. 1960; Maltusch an Keller, 15.3.1960, ADW, HGSt, SP-S XXV 1: 103-1/1; Collmer an Ohl, 6. 6.1960, ADW, HGSt, SP-S XXV 1: 427-1/1.

176 Vgl. Antrag des Landes Schleswig-Holstein vom 16.3.1960, BR 1960 Drucksachen, Drs. 53/5/60.

177 Kiesinger an Schröder, 16.3.1960, BAK, B 106/20647.

178 Vgl. BR 1960 Sten. Ber., S. 338.

179 Vgl. ebenda, S.339f. BldW 107 (1960), S. 102. In $\ 10$ Abs. 5 wurde noch klarer herausgestellt, daß die Zusammenarbeit im Einzelfall wie für allgemeine Aufgaben gelten solle, und in $\$ 86$ verdeutlicht, daß der Begriff der „Einrichtungen“ auch halboffene Einrichtungen und ambulante Maßnahmen etwa der Haus- und Familienpflege umfaßte; vgl. Antrag des Landes Rheinland-Pfalz vom 16.3.1960, BR 1960 Drucksachen, Drs. 53/7/60. 
Andere wichtige Vorschläge seiner beteiligten Ausschüsse hingegen übernahm der Bundesrat: Die Erhöhung der Einkommensgrenzen, auch bei der Blindenhilfe, die weitere Einschränkung der Kostenersatzpflicht, Verbesserungen bei der Ausbildungshilfe, die Einschränkung der vorbeugenden Gesundheitsfürsorge auf eine Kann-Bestimmung und - eifersüchtig um die Wahrung der Länderkompetenzen bemüht - die Streichung der Bestimmungen über das Fachpersonal, die Finanzierung und die Festschreibung der Städte und Kreise als örtliche Träger. ${ }^{180}$ Dementsprechend forderte der Bundesrat die Reduzierung der Gefährdetenfürsorge auf eine nicht näher geregelte Kann-Bestimmung, womit die Ministerpräsidenten den Vorschlägen der Fürsorgereferenten diametral widersprachen, aber den verfassungspolitischen Einwänden des Rechtsausschusses folgten. ${ }^{181}$ Die Hilfe für junge Menschen hingegen sollte zwar nicht als eigenständige Hilfe geregelt, aber im Rahmen der Hilfe zum Lebensunterhalt eine Vorschrift über den besonderen Bedarf von Minderjährigen aufgenommen werden. ${ }^{182}$

In der Subsidiaritätsfrage hatten sich damit parteipolitische Loyalität und kirchenpolitische Erwägungen bei den CDU-geführten Landesregierungen als stärker als kommunalpolitische Interessen erwiesen und zugunsten der Bundesregierung ausgewirkt. Wo aber vermeintliche oder tatsächliche Beschränkungen der eigenen Finanz- und Verwaltungshoheit oder Gesetzgebungskompetenz zu befürchten waren, standen auch diese Landesregierungen in Opposition zum Bund. Daß auch jenseits des Subsidiaritätsproblems die kommunalen Belange hier nicht vorrangig interessierten, mag die Tatsache belegen, daß der Bundesrat entgegen den Wünschen seines Finanzausschusses eine Reihe von Leistungsverbesserungen zu Lasten der Sozialhilfeträger beschlossen hatte. Abgesehen von den genannten und weiteren meist rechtstechnischen oder redaktionellen, insgesamt dann 68 Änderungswünschen erhob der Bundesrat gegen den Entwurf als ganzen keine Einwendungen. ${ }^{183}$ Das bedeutete nichts anderes, als daß die Länder trotz aller Rück-

180 Vgl. BR 1960 Sten. Ber., S.339ff.; Stellungnahme des Bundesrates zum Entwurf eines BSHG, BT, 3. Wp. 1957, Anlagen, Bd.67, Drs. 1799.

181 Der Rechtsausschuß argumentierte, daß eine Hilfe ohne jede Rücksicht auf die materielle Lage des Betroffenen und die vorgesehenen Zwangsmaßnahmen nicht durch den Fürsorgebegriff von Art. 74 Nr.7 GG abgedeckt seien und dem Bund damit die Gesetzgebungskompetenz fehle; vgl. Empfehlungen des federführenden Ausschusses für Innere Angelegenheiten, des Ausschusses für Arbeit und Sozialpolitik, des Finanzausschusses und des Rechtsausschusses vom 11.3.1960, BR 1960 Drs. 53/1/60.

$182 \mathbb{1 2}$ (Notwendiger Lebensunterhalt) sollte um einen zweiten Absatz ergänzt werden, wonach bei Kindern und Jugendlichen der notwendige Lebensunterhalt „auch den besonderen, vor allem den durch das Wachstum bedingten Bedarf“ umfasse; begründet wurde dies mit den Erfordernissen einer einheitlichen Familienfürsorge; vgl. Stellungnahme des Bundesrates zum BSHG-Entwurf, S.69, BT, 3.Wp. 1957, Anlagen, Bd.67, Drs. 1799.

$183 \mathrm{Vgl}$. Schreiben des saarländischen Ministerpräsidenten und amtierenden Bundesratspräsidenten Franz Josef Röder an den Bundeskanzler vom 18.3.1960, Abschrift, BR 1960 Drucksachen, Drs. 53/60, Beschluß. Der ursprünglich eher für eine allgemeine politische Stellungnahme gedachte erste Durchgang im Bundesrat diente Ende der fünfziger Jahre längst dazu, zahlreiche fachliche und formalrechtliche Änderungswünsche geltend zu machen, wofür die Drei-Wochen-Frist kaum hinreichte; vgl. Katzenstein, Erscheinungsformen, S. 598. 
zugsgefechte auf dem Gebiet der Verwaltungshoheit grundsätzlich bereit waren, dem mit dem BSHG verfolgten Ziel einer größeren Rechtseinheit und stärkeren Leistungsangleichung auf dem Gebiet des Fürsorgerechts zuzustimmen.

Die Bundesregierung stimmte rund zwei Dritteln der Änderungsvorschläge des Bundesrates zu. Abgelehnt wurde die weitgehende Streichung der Gefährdetenfürsorge, da es auch andere als wirtschaftliche Notlagen gebe; die Abschwächung der vorbeugenden Gesundheitsfürsorge, da Prophylaxe billiger als Heilung sei; die erhöhte Einkommensgrenze für die Ausbildungshilfe wegen der Abstimmung mit den Leistungen nach anderen Gesetzen; die Streichung der Bestimmungen über die örtlichen Träger und die Fachkräfte wegen der zentralen Bedeutung für die erfolgreiche Durchführung des Gesetzes; nicht zuletzt die Modifikationen in den $\mathbb{S} 10$ und 86 sowie die stärkere Beschränkung der Kostenersatzpflicht, wobei formaljuristische Gründe geltend gemacht wurden, tatsächlich aber die so mühsam ausgehandelten Kompromisse in zwei zentralen Fragen nicht wieder gefährdet werden sollten. ${ }^{184}$ Am 20. April 1960 ging der Regierungsentwurf mit den Änderungsvorschlägen und der Auffassung der Bundesregierung dazu an den Bundestag. ${ }^{185}$

Damit war die Zuständigkeit für den BSHG-Entwurf endlich dort, wo sie nach der klassischen Lehre von der Gewaltenteilung eigentlich hingehört: im Parlament. Tatsächlich war die bisherige Genese der Reform abermals ein treffender Beleg für die Beobachtung von der Dominanz der Bundesregierung und ihres bürokratischen Apparates im Gesetzgebungsprozeß, von der auch die Sozialpolitik keine Ausnahme machte. ${ }^{186}$ Bisher hatten sich nur einzelne Bundestagsabgeordnete wie Maria Niggemeyer, Peter Horn, Friedrich-Wilhelm Willeke, Helene Weber, Ernst von Bodelschwingh und Emmi Welter (alle CDU), ferner Helene Wessel, Willy Könen und Lisa Korspeter (alle SPD) vor allem über den DV, im Falle der Sozialdemokraten auch im Rahmen der AWO, schon zuvor mit einigen Reformbereichen näher befaßt. ${ }^{187}$ Doch selbst die Aufforderung des Bundestages vom Januar 1957 an die Regierung, den Entwurf für ein neues Bundesfürsorgegesetz vorzu-

${ }^{184}$ Vgl. Auffassung der Bundesregierung zu den Änderungsvorschlägen des Bundesrates, S. 82ff., BT, 3. Wp. 1957, Anlagen, Bd.67, Drs. 1799; Gottschick, Entwurf.

185 Vgl. Erhard in Stellvertretung des Bundeskanzlers an den Präsidenten des Bundestages, 20.4.1960, BT, 3. Wp. 1957, Anlagen, Bd.67, Drs. 1799, S. 1.

186 Vgl. ausführlich Hockerts, Entscheidungen, S.124ff., der dies aufgrund der engen „Interessen- und Aktionseinheit“ (S.128) von Regierung und Parlamentsmehrheit als Funktionswandel, nicht aber Funktionsverlust des Parlaments begreift.

187 Für die gesamten sozialpolitischen Arbeitskreise der großen Fraktionen hingegen ist eine Erörterung der BSHG-Referentenentwürfe nicht belegt: Die Protokolle des Sozialpolitischen Arbeitskreises der CDU/CSU sind in den einschlägigen Beständen für 1959 und 1960 ohnehin nicht überliefert, doch gibt es auch in den Unterlagen des Arbeitskreises zum BSHG, ACDP, CDU/CSU-Fraktion AK IV, VIII-005-106/1, keine entsprechenden Hinweise. Einzig zwei Gespräche von Fürsorgespezialisten und des Vorsitzenden des Arbeitskreises Horn mit Duntze Anfang Juni 1959 sowie Anfang November 1959 über die Subsidiaritätsfrage sind belegt; vgl. Vermerk Abteilungsleiter V vom 1.7. 1959, BAK, B 106/20647; Ranke an Collmer, 11.11.1959, Abschrift, ADW, HGSt 3930. Für die SPD vgl. die Protokolle und Unterlagen des Arbeitskreises Sozialpolitik 1958 und 1959 in: AdsD, SPD-BTF 3. Wp., 85 und 86. 
legen, war nur die nachträgliche offizielle Autorisierung von Reformarbeiten, die im Innenministerium seit mehr als einem Jahr ohnehin im Gange waren.

Auch bei den Ausschußberatungen wollten und konnten die zuständigen Parlamentarier nicht auf die Kooperation mit dem Bundesinnenministerium verzichten und stimmten mit Gottschick bereits Anfang April das weitere Procedere ab. ${ }^{188}$ Für den federführenden Ausschuß für Kommunalpolitik und öffentliche Fürsorge rechneten dessen Vorsitzender Willeke und Maria Niggemeyer mit einer langwierigen Beratung und hofften daher, daß bis auf den ohnehin zu beteiligenden Haushaltsausschuß keine weiteren Ausschüsse hinzugezogen würden. Ziel der christdemokratischen Bundestagsfraktion war es, das lange vorbereitete BSHG auf jeden Fall noch in der laufenden Legislaturperiode $\mathrm{zu}$ verabschieden, und zwar möglichst mit den Stimmen der SPD. ${ }^{189}$ Angesichts der im Bundesrat nun ganz eindeutig parteipolitischen Divergenzen in der Subsidiaritätsfrage würde das allerdings nicht einfach sein: Nachdem Franz Klein Ende März in der Zeitschrift der KPV der CDU den BSHG-Entwurf als Verwirklichung der katholischen Forderungen gewürdigt ${ }^{190}$ und Kardinal Frings Anfang April im Kölner Dom verkündet hatte, die „sozialistischen Staaten im Bundesrat [hätten] die Paragraphen, die besonders zum Schutz der freien Wohlfahrtspflege [...] eingefügt waren, herausschiessen wollen "191, suchte Auerbach den Schulterschluß mit dem DST und bemühte sich abermals, die beteiligten Vertreter der evangelischen Kirche gegen die katholischen Vorstellungen zu mobilisieren. ${ }^{192}$ Klein hatte in seinem Artikel erklärt, beide Kirchen hätten durch ihre Bonner Vertretungen dem Regierungsentwurf grundsätzlich zugestimmt. ${ }^{193}$ Das hielt Auerbach angesichts der kritischen Äußerungen Collmers für fraglich und forderte Collmer, Ohl und die Kirchenkanzlei auf, gegebenenfalls Klein zu einer Richtigstellung zu veranlassen, damit bei der geplanten baldigen Anhörung der freien Verbände vor dem Bundestagsausschuß diese Unterschiede zwischen katholischer und evangelischer Auffassung deutlich werden könnten. ${ }^{194}$ Auch unter den evangelischen Unionsabge-

188 Vgl., auch zum Folgenden, Vermerk Gottschick vom 7.4.1960 über ein Gespräch mit Willeke und Niggemeyer, BAK, B 106/20653a.

189 Vgl. ebenda; ferner Vermerk Gottschick vom 3.5.1960 über die Sitzung des Arbeitskreises IV der CDU/CSU, ebenda.

190 Vgl. Franz Klein, Regierungsentwurf.

191 Vgl. Meldung der Katholischen Nachrichten-Agentur (KNA) Nr. 81 vom 5. 4.1960, Abschrift von Abschrift in: ADW, HGSt, SP-S XXV 1: 426-1/1.

$192 \mathrm{Vgl}$. den Briefwechsel zwischen Auerbach und Oel zwischen dem 13. und 31.5.1960, LAB, B Rep. 142-9, 1284. In einem ausführlichen Brief an Frings vom 29. 4.1960 rechtfertigte Auerbach außerdem das Vorgehen Niedersachsens im Bundesrat als gerade der Eigenständigkeit und Freiheit der Wohlfahrtspflege wie der Kirchen selbst geschuldet; in „Erinnerung an die Erfahrungen der Kirchenverfolgung durch totalitäre Regierungen“" solle erst gar nicht der Eindruck erweckt werden, ein Sozialgesetz dürfe überhaupt die Stellung der Kirchen berühren, wie es die derzeitige Fassung von $\mathbb{1 0}$ Abs. 1 u. 2. suggeriere, Abschrift, ADW, HGSt, SP-S XXV 1: 426-1/1.

193 Vgl. Franz Klein, Regierungsentwurf, S. 166.

194 Auerbach an Collmer, 3.5.1960 und 13.5.1960, ADW, HGSt, SP-S XXV 1: 426-1/1; Auerbach an Ohl, 13.5.1960, Abschrift, ADW, HGSt, SP-S XXV 1:427-1/1; Auerbach an Maltusch, 13.5.1960, Abschrift; Maltusch an Collmer, 14.5.1960, ADW, HGSt, SP-S XXV 1:103-1/1; Ohl an Ranke, 26.5.1960, ADW, HGSt, SP-S XXV 1: 427-1/1. 
ordneten bestand hier Klärungsbedarf, und Bodelschwingh beschwerte sich bei Ranke und der Bonner Verbindungsstelle, daß kein evangelischer Sachverständiger der Einladung zur ersten Beratung des Entwurfs im Sozialpolitischen Arbeitskreis seiner Fraktion gefolgt sei. ${ }^{195}$

Tatsächlich bestanden auf evangelischer Seite nach wie vor gewisse Unterschiede bei der Bewertung dieser Frage zwischen Kirchenkanzlei und Diakonie, die jedoch nicht nach außen getragen und keineswegs zugunsten der SPD-Linie umgemünzt werden sollten. Die daraus resultierende Zurückhaltung und dilatorische Behandlung der Frage durch die Diakonie-Vertreter führte allerdings dazu, daß Rankes Vorgehen von außen als repräsentativ für die evangelische Kirche wahrgenommen und daher eine breite Übereinstimmung beider Kirchen konstatiert werden konnte, so daß auch Kleins Äußerung ihre Berechtigung hatte. ${ }^{196}$

Trotz der immer stärkeren konfessions- und kirchenpolitischen Akzentuierung der Fürsorgereform blieb diese auch weiterhin in den Fraktionen und Arbeitskreisen der großen Parteien ein Thema für den kleinen Kreis interessierter Spezialisten. Auf den Sitzungen der Gesamtfraktion sowie des Vorstands der CDU/CSU unmittelbar vor der ersten Lesung des Entwurfs war das BSHG jedenfalls nicht von Belang ${ }^{197}$; auch bei der SPD ging es nur um die Festsetzung des Abgeordneten (Könen), der dazu sprechen sollte. ${ }^{198}$ Ähnliches galt für die einschlägigen Arbeitskreise der Bundesparteien, denen bei der CDU Collmer, bei der SPD Auerbach, also zwei ausgewiesene Fürsorgepolitiker angehörten. ${ }^{199}$ Immerhin beriet bei den Christdemokraten jetzt der Sozialpolitische Arbeitskreis der Fraktion (Arbeitskreis IV) den Regierungsentwurf und benannte Maria Niggemeyer als Berichterstatterin. ${ }^{200}$ Aufgrund der lückenhaften Quellenlage ist die weitere Einflußnahme des Arbeitskreises auf die Arbeit des zuständigen Bundestagsausschusses nicht unmittelbar zu belegen; vieles deutet aber darauf hin, daß die Fraktionsvertreter im Bundestagsausschuß nicht, wie für die heutige parla-

195 Vgl. Horn an Ranke, 31.3.1960, ACDP, CDU/CSU-Fraktion AK IV, VIII-005-106/1; Vermerk Brügemann vom 5.4.1960; Brügemann an Münchmeyer, 12.4.1960; Vermerk Münchmeyer vom 14.4.1960; Brügemann an Collmer, 29.4.1960, mit Anlage, ADW, HGSt, SP-S XXV 1: 160-1/2.

196 Vgl. Vermerk Heun vom 4.4.1960, ADW, HGSt, SP-S XXV 1: 102-1/1; Ohl an Collmer, 26. 5.1960; Ranke an Ohl, 1.6.1960, ADW, HGSt, SP-S XXV 1: 427-1/1. Collmer $\mathrm{maß}$ mittlerweile dem $\mathbb{S} 10$ ohnehin vor allem deklaratorische Bedeutung bei und hielt die Bedenken Auerbachs für stark übertrieben; vgl. Collmer an Maltusch, 24.5.1960, ADW, HGSt, SP-S XXV 1: 103-1/1; Collmer an Ohl, 6.6.1960, ADW, HGSt, SP-S XXV 1: 427-1/1.

197 Vgl. etwa die Protokolle der Sitzungen des Fraktionsvorstands am 2.5.1960 und der Fraktion am 3.5.1960, in: CDU/CSU-Fraktion 1957-1961, S. 600ff.

198 Vgl. Fraktionssitzung am 3.5.1960, in: SPD-Fraktion 1957-1961, S. 432.

199 Vgl. die damaligen Sitzungsunterlagen und Protokolle der Sozialpolitischen Ausschüsse der CDU, ACDP, Bundesgeschäftsstelle, VII-004-090/2, und beim SPD-Parteivorstand, AdsD, SPD-Parteivorstand, 01987 bis 10990 sowie 01582.

200 Vgl. Protokoll der Sitzung des Sozialpolitischen Arbeitskreises am 3.5.1960, ACDP, CDU/CSU-Fraktion AK IV, VIII-005-106/1; Vermerk Gottschick über die Sitzung [o.D., vermutlich 4.5.1960], BAK, B 106/20653a; zur Sitzung des Arbeitskreises am 5.4. 1960 die Vermerke Heun, 4.4.1960, ADW, HGSt, SP-S XXV 1:102-1/1, und Brügemann, 5. 4.1960, ADW, HGSt, SP-S XXV 1:160-1/2. 
mentarische Praxis als Modellfall beschrieben, dort vor allem eine von der Fraktion vorgegebene Linie umzusetzen suchten, sondern daß bei der politisch eher marginalen und komplizierten Frage der Fürsorgereform der Gang der Entscheidung umgekehrt verlief und die Fürsorgespezialisten dem Arbeitskreis und der Gesamtfraktion die Vorgaben für deren offizielle Beschlüsse lieferten. ${ }^{201}$ Das zeigte sich insbesondere bei der Frage der Einkommensgrenzen und dem Pflegegeld. 202

Bei der SPD lagen die Dinge im Prinzip ähnlich: Allerdings war es hier der Spezialisten-Pool der parteinahen AWO, der zusammen mit den entsprechenden Bundestagsabgeordneten und weiteren SPD-Fachleuten die Positionen im wesentlichen bestimmte. Ein von dem SPD-Fürsorgeexperten und Geschäftsführer der AWO im Regierungsbezirk Düsseldorf Willy Könen geleiteter Arbeitskreis beim AWO-Hauptausschuß aus führenden AWO-Vertreterinnen und den Expertinnen der Fraktion, dem auch Auerbach und Anton Oel vom DST angehörten, beriet parallel zum Bundestagsausschuß den Gesetzentwurf und bereitete die Änderungsanträge der SPD-Vertreter dort vor. ${ }^{203}$ Auch hier segnete der sozialpolitische Arbeitskreis der Bundestagsfraktion diese Positionen dann erst am Ende der Ausschußberatungen seinerseits ab. ${ }^{204}$

Am 4. Mai 1960 fand die erste Lesung des BSHG-Entwurfs im Bundestag statt. Innenminister Schröder deutete ihn als endgültigen Abschied von der Armenfürsorge: Ein sozialer Rechtsstaat wie die Bundesrepublik, „der jedem seiner Bürger das Recht auf freie Entfaltung der Persönlichkeit sichert, muß alles daransetzen, dem Notleidenden aus seiner Unfreiheit herauszuhelfen." Dabei genüge es nicht mehr, Menschen ohne eigenes Einkommen „nur die notwendigsten Dinge des Lebensunterhalts“ zukommen zu lassen, sondern es gehöre „zu den Aufgaben der Allgemeinheit, sich auch der Menschen anzunehmen, die zwar ihr tägliches Brot haben mögen, sich aber in einer sozialen Notlage anderer Art befinden, die ihnen verwehrt, ein Leben in der Gemeinschaft zu führen, wie es den Anschauungen unseres Volkes entspräche“. Etwaigen Befürchtungen aus den eigenen Fraktionsreihen kam Schröder dabei mit dem Hinweis zuvor, es werde „der Gedanke der

$201 \mathrm{Zu}$ den Einflußmöglichkeiten der Experten auf die Meinungsbildung der Gesamtfraktion bei diffizilen und nicht auf wenige politische Vorgaben reduzierbaren Materien vgl. Melzer, Vorbereitung, S.1137ff.; Zeh, Ausschußsystem, S. 1100.

202 Vgl. etwa Niggemeyer an Krone, 29.1.1961; Protokoll der Sitzung des Sozialpolitischen Arbeitskreises am 28.2.1961, mit Anlage Willeke vom 24.2.1961, ACDP, CDU/CSUFraktion AK IV, VIII-005-160/1.

203 Vgl. die Protokolle der Sitzungen des Arbeitskreises für Fragen der Neuordnung des Sozialhilferechts der AWO am 28.4.1960 und des Fachausschusses „Wohlfahrtspflege und Sozialpolitik" beim AWO-Hauptausschuß am 29.10.1960, AdsD, SPD-BTF 3. Wp., 133, sowie am 9.12.1960 und 21.1.1961, AdsD, SPD-BTF 3. Wp., 136. Leider sind auch für die SPD-Fraktion die Protokolle des Arbeitskreises Sozialpolitik von 1960 nicht im Bestand der Bundestagsfraktion im AdsD überliefert. Könen, Weg, S. 407, berichtet, daß der BSHG-Entwurf in „enger Zusammenarbeit" von Fraktionsarbeitskreis und den Fachausschüssen der Partei und der AWO beraten worden sei.

${ }^{204}$ Vgl. die handschriftlichen Notizen vermutlich von Konrad Schayer, Assistent des Arbeitskreises Sozialpolitik, über dessen Sitzungen am 7.3. und 17.4.1961, sowie die Protokolle der Sitzungen am 28.4. und 2.5.1961, AdsD, SPD-BTF 3. Wp., 136. 
Eingliederung oder Wiedereingliederung des Hilfeempfängers in Gesellschaft und Arbeit mit an die Spitze des Entwurfs gestellt und gleichzeitig jedem versorgungsstaatlichen Denken eine Absage erteilt". Das heikle Thema der Subsidiaritätsfrage versuchte der Minister zu entschärfen, indem er die vorgesehenen Regelungen als Versuch interpretierte, das „partnerschaftliche Verhältnis zwischen den Trägern der Sozialhilfe und der freien Wohlfahrtspflege zu sichern und dazu beizutragen, daß auch in Zukunft die freie Wohlfahrtspflege in der Lage bleibt, ihre so bedeutsame Tätigkeit durchzuführen“.205

Auch Maria Niggemeyer wies für die Unionsfraktion Befürchtungen vor einer „Konfessionalisierung“ der sozialen Arbeit zurück, da sämtliche freien Verbände beteiligt werden sollten. ${ }^{206}$ In ihrer erwartungsgemäß positiven Bewertung des Entwurfs bezog sie sich auf das Verfassungsgebot, „die soziale Stellung des hilfsbedürftigen Menschen" seiner Würde gemäß zu sichern, dem allerdings die individuelle Pflicht zur Selbsthilfe korreliere. ${ }^{207}$ Könen, der für die SPD sprach, tat sich mit der Oppositionsrolle insofern etwas schwer, als er viele der neuartigen Regelungen des Entwurfs auf das Konto des SPD-Sozialplans verbuchte und für die Ausschußverhandlungen weniger prinzipielle als Kritik an Einzelpunkten anmelden konnte: etwa bei den Regelsätzen oder der Blindenhilfe und natürlich der Stellung der freien Wohlfahrtspflege. ${ }^{208}$ Sehr viel grundsätzlicher war demgegenüber die Gegenrede des FDP-Abgeordneten Rutschke, der wie Niggemeyer und Könen dem Kommunalpolitischen Ausschuß angehörte und im Bundestag ganz im Sinne des DLT zu sprechen schien. Es sei zwar „eine schöne Sache, sehr warmherzig über die Not von Menschen zu reden und zu sagen, man wolle ihnen unbedingt helfen“, man solle aber „dabei nicht die Realität vergessen“: Heute sei persönliche Not vielfach individuell verschuldet, man dürfe daher weder grundsätzlich auf die Rückzahlungspflicht verzichten noch eine Nivellierung der Leistungen betreiben. Mit dem Rechtsanspruch werde „die Mildtätigkeit des Bürgers nunmehr verstaatlicht". Vor allem solle die Bundesregierung nicht im Blick auf die Bundestagswahl Leistungen in einem Maße vorsehen, das bei schlechter Konjunktur „zu einer finanziellen Notlage der Gemeinden führen“ müsse. ${ }^{209}$ Nach dieser unspektakulären ersten Lesung wurde der Entwurf federführend an den Ausschuß für Kommunalpolitik und öffentliche Fürsorge sowie geschäftsordnungsmäßig an den Haushaltsausschuß und auf Antrag Könens mitberatend an den Ausschuß für Gesundheitsfragen überwiesen.210

Eine Woche später begann der Kommunalpolitische Ausschuß die Beratung. ${ }^{211}$ Von dessen 29 ordentlichen Mitgliedern waren entsprechend der Sitzverteilung im Bundestag 17 Abgeordnete der Regierungskoalition (13 CDU, 3 CSU, 1 DP) und

205 BT, 3. Wp. 1957, Sten. Ber., Bd. 45, S. 6254.

206 Ebenda, S. 6259.

207 Ebenda, S. 6257 (Hervorhebung im Original).

208 Vgl. ebenda, S. $6259 \mathrm{ff}$.

209 Ebenda, S. 6261.

210 Vgl. ebenda, S. 6262.

$211 \mathrm{Zu}$ Zusammensetzung, Aufgabe und Rolle der Bundestagsausschüsse im Gesetzgebungsverfahren vgl. allgemein Zeh, Ausschußsystem; Dach, Ausschußverfahren. 
12 der Opposition (10 SPD, 2 FDP). ${ }^{212}$ Hinzu kam die gleiche Zahl von stellvertretenden Mitgliedern, die ebenfalls an den Sitzungen teilnehmen konnten, aber nur stimmberechtigt waren, wenn nicht genügend ordentliche Mitglieder der eigenen Fraktion anwesend waren. Wie erwähnt, war der Ausschuß 1957 aus zwei Bundestagsausschüssen hervorgegangen. War dem politisch eher bedeutungslosen Kommunalausschuß bis dato vorgeworfen worden, zu eng mit den kommunalen Spitzenverbänden zu kooperieren ${ }^{213}$, hatte der Fürsorgeausschuß als sozialpolitischer Fachausschuß gearbeitet, wenn auch stets über deren Vorsitzende Niggemeyer und den DV ein fachlicher Kontakt zu den kommunalen Spitzenverbänden gewährleistet war. Diese zum Teil divergierenden Interessen waren nun unter dem Dach eines neuen Ausschusses vereinigt. Insgesamt dominierten im neuen Ausschuß unter den ordentlichen Mitgliedern die genuinen Kommunalvertreter: Zwanzig Abgeordneten aus allen Fraktionen mit kommunaler Orientierung Bürgermeister, Kreistagsabgeordnete, Stadträte - standen nur sieben ausgesprochene Fürsorgespezialisten gegenüber. ${ }^{214}$ Doch bei der Beratung des BSHG-Entwurfs überließen die Kommunalvertreter das Feld im wesentlichen den Fürsorgeexperten ihrer Fraktion: von der CDU Maria Niggemeyer, Helene Weber und Emmi Welter und als zunächst stellvertretendes Mitglied Ernst von Bodelschwingh, von der SPD Könen, Elfriede Eilers, Franziska Bennemann sowie Helene Wessel und Hans Lautenschlager (beide stellvertretend) mit teilweise engen Bindungen $\mathrm{zu}$ den christlichen Wohlfahrtsverbänden auf christdemokratischer und zur AWO auf sozialdemokratischer Seite. ${ }^{215}$ Mit Niggemeyer und Könen fungierten auch jeweils führende Fürsorgespezialisten als Berichterstatter des Ausschusses und Obleute und konnten die Linie der eigenen Fraktion dort entscheidend prägen. ${ }^{216}$

Diese Konstellation war einer Berücksichtigung von Forderungen nach einer weiteren Leistungsreduktion, wie sie vor allem von den ländlichen Kommunen nach wie vor erhoben wurden, nicht unbedingt förderlich; umgekehrt hatte Maria

212 Vgl. Handbuch des Deutschen Bundestages 1958, S.186. Mit Auflösung der Fraktion der DP schied der stellvertretende Ausschußvorsitzende Helmuth Schranz (DP) Anfang November 1960 als ordentliches Mitglied aus, den stellvertretenden Vorsitz übernahm jetzt Könen, Nachfolger für Schranz wurde der CDU-Abgeordnete Etzenbach; vgl. Kurzprotokolle des Ausschusses für Kommunalpolitik und öffentliche Fürsorge - im Folgenden kurz „Kommunalpolitischer Ausschuß“ -, 9. und 10.11.1960, PA, Gesetzesmaterialien III/349 A1.

213 Vgl. Bertram, Staatspolitik, S. 176ff.

214 Ermittelt anhand der Kurzbiographien der Abgeordneten, in: Handbuch des Deutschen Bundestages 1958. Acht Abgeordnete hatten bereits zuvor dem Kommunalausschuß, vier dem Fürsorgeausschuß und drei beiden Ausschüssen angehört.

215 Die evangelischen Abgeordneten Emmi Welter und Bodelschwingh besprachen das weitere Vorgehen außerdem mehrmals mit Collmer; vgl. das Memorandum der Hauptgeschäftsstelle von Innerer Mission/Hilfswerk über deren Mitwirkung bei der Fürsorgerechtsreform, o.D., Anlage zu Rundschreiben der Hauptgeschäftsstelle vom 19.10.1961, ADW, HGSt, SP-S XXV 1: 463-1/1.

216 Vgl. Kurzprotokoll Kommunalpolitischer Ausschuß, 11.5.1960, PA, Gesetzesmaterialien III/349 A1. Zu Könen vgl. auch Wolfgang Hölscher, Einleitung, in: SPD-Fraktion, S.XXV; zu den Einflußmöglichkeiten der Obleute vgl. Dach, Ausschußverfahren, S. $1112 f ., 1118 f$. 
Niggemeyer aber bereits bei der ersten Lesung im Bundestag versichert, daß man deren Belange nicht aus den Augen verlieren werde. ${ }^{217}$ Schließlich war die Union in den Landkreisen vielfach stark vertreten, so daß auch aus parteipolitischen Erwägungen hier gewisse Rücksichten zu üben waren. Vehementer Fürsprecher traditioneller Fürsorgeinteressen, wie sie vor allem in den bayerischen kommunalen Spitzenverbänden beheimatet waren, war im Ausschuß der ehemalige Landrat und Kaufbeurener Kreistagsabgeordnete Josef Spies (CSU), zum Teil unterstützt durch Kurt Spitzmüller, ehemals Mitglied im Kreistag im badischen Wolfach von der FDP. Der Vorsitzende des Ausschusses Willeke war als Generalsekretär der KPV sogar hauptamtlicher Interessenvertreter der Kommunen. In der vor allem strittigen Subsidiaritätsfrage aber sollte dies nur von untergeordneter Bedeutung sein: Willeke war katholisch und hatte Heimat und Wahlkreis in Nordrhein-Westfalen, einem Bundesland also, wo die konfessionellen Träger seit jeher stark verankert waren. Vor allem aber hatte die KPV von Anfang an den Vorrang der freien Träger in allen Wohlfahrtsangelegenheiten befürwortet, so daß Willeke hier kaum Interessenkonflikte drohten und er eng mit dem Katholischen Büro kooperieren konnte. ${ }^{218}$

Für eine Rückkoppelung an kommunale Belange sorgten nicht zuletzt die wichtigen Querverbindungen zum DV: Niggemeyer und Könen waren nicht nur Mitglied im Hauptausschuß des DV, sondern auch im Fachausschuß I, in dem neben exponierten Fürsorgeexperten der Länder führende Vertreter des DLT, vor allem aber des DST sowie der Spitzenverbände der freien Wohlfahrtspflege versammelt waren und der unter dem Vorsitz von Muthesius für den DV die Stellungnahme für den Bundestagsausschuß erarbeiten sollte. ${ }^{219}$ Helene Weber schließlich gehörte dem Vorstand des DV an. Die aus der bisherigen Reformarbeit wohlvertraute Vernetzung von Fürsorgeexperten des Bundestages, der Länder, Kommunen, freien Wohlfahrtspflege und des Bundesinnenministeriums wurde also auch während der parlamentarischen Beratungsphase weitergeführt.

Nachdem Duntze in der ersten Sitzung des Bundestagsausschusses am 11. Mai 1960 den Entwurf ausführlich erläutert hatte, konnten im Juni Vertreter der vier kommunalen Spitzenverbände, der beiden christlichen Wohlfahrtsverbände sowie der AWO ihre Stellungnahmen vor dem Ausschuß abgeben. ${ }^{220}$ Anders als zunächst von Willeke und Niggemeyer beabsichtigt, war Muthesius nicht ebenfalls darunter: Vermutlich sollten erst die Beratungen in den Fachausschüssen und im DV-Hauptausschuß im November abgewartet werden, ehe er im Namen des DV offiziell Position bezog, zumal nicht nur Maria Niggemeyer die Hoffnung hegte, auf der parteipolitisch neutralen Ebene des DV könne man eher Kompromisse finden.221

217 Vgl. BT, 3. Wp. 1957, Sten. Ber., Bd. 45, S. 6258.

218 Mündliche Auskunft Frey, 23.7.2002.

219 Weitere Mitglieder im Fachausschuß I waren u.a. Bangert, Collmer, Flamm, Hoppe, Jellinghaus, Keese, Klein, Kobus, Lotte Lemke, Oel, Else Opp, Käthe Petersen, Käte Pluskat, Scheffler und Wehlitz; vgl. Bericht über die Sitzung des Fachausschusses I am 17./18. 5. 1960, ADW, HGSt, SP-S XXV 1: 110-1/2.

220 Vgl. Kurzprotokolle Kommunalpolitischer Ausschuß, 11.5. und 23.6.1960, PA, Gesetzesmaterialien III/349 A1.

221 Vgl. NDV (1961), S. 11; Wehlitz, Entwurf, S. 2. 
Die kommunalen Verbände hatten sich auf der Basis ihres Votums für den Bundesrat unter Federführung des DST auf eine gemeinsame Stellungnahme geeinigt, an der auch Ministerialrat Weller von der Sozialabteilung mitgewirkt hatte 222: Von den Kommunen wurde der Regierungsentwurf zwar „grundsätzlich begrüßt", in wesentlichen Punkten aber weiterhin deutlicher Protest geltend gemacht: gegen die Regelung des Verhältnisses zur freien Wohlfahrtspflege, die Blindenhilfe und die unzureichend gesicherte Finanzierung. ${ }^{223}$ Angesichts der erfolglosen Bemühungen um eine Änderung der Finanzverfassung hielten die Kommunen jetzt auch Bundeszuschüsse für wünschenswert. Wie stets im Bundesfinanzministerium befürchtet, befürworteten DLT und bayerische Verbände außerdem eine Verlängerung der Zahlungen für die Kriegsfolgenhilfe. ${ }^{224}$ Ferner forderten die Kommunen u.a., bei der Festsetzung der Regelsätze beteiligt zu werden. Uneins war man nach wie vor bei der Kostenersatzpflicht und der Aufgabenverteilung auf örtliche und überörtliche Träger.

Vor allem aber war die prinzipielle Bewertung des Entwurfs sehr unterschiedlich geblieben: Während Oel für den DST eigentlich nur die Regelungen über die freie Wohlfahrtspflege für im Kern verfehlt hielt ${ }^{225}$, erhob Bangert entsprechend den Vorgaben des DLT-Präsidiums die bekannten Vorbehalte gegen ein Gesetz, das den zwischenmenschlichen Zusammenhalt auf dem Lande gefährde und die „Niederlegung gewisser sozial-ethischer Schranken“ betreibe. Dabei machte er den Kompromißvorschlag, bei der Gewährung der Hilfe zum Lebensunterhalt, die mittlerweile „in der überwiegenden Zahl der Fälle auf ein Verschulden des in Not Geratenen, oft auch auf eine gemeinschaftswidrige Grundeinstellung" zurückzuführen sei, diese Schranken durch Kostenersatz, rigide Bedürftigkeitsprüfung und Heranziehung Unterhaltspflichtiger aufrechtzuerhalten; die Hilfen in besonderen Lebenslagen hingegen, „die mit einem Schuldigwerden am eigenen Notstand gar nichts oder nur sehr wenig zu tun haben", sollten von diesen Beschränkungen sogar noch weiter befreit werden.226 Dieser Vorschlag dürfte eher der innerverbandlichen Stimmungslage geschuldet sein als der Hoffnung auf massive finanzielle Einsparungen, wurde doch allgemein mit weiter sinkender Bedeu-

222 Vgl. Niederschrift über die Sitzung des DST-Arbeitskreises „Fürsorgerecht“ am 30.3. 1960, mit Anlage; die Briefwechsel zwischen der DST-Geschäftsstelle und den Mitgliedern des DST-Sozialausschusses bzw. den Landesverbände zwischen dem 27.4. und 10.5.1960; DST, Abteilung 9 an Abteilung 4, 27.4.1960; den Briefwechsel zwischen Bundesvereinigung der Kommunalen Spitzenverbände und den einzelnen Spitzenverbänden zwischen dem 28.4. und 16.5.1960; Vermerk Kelm vom 9.5.1960; Vermerke Lehmann-Grube vom 11. und 30.5.1960; Niederschrift über die Sitzung des DST-Sozialausschusses am 12./13.5.1960, Auszug, LAB, B Rep. 142-9, 1284. Weller hatte erfolgreich darauf gedrängt, die Forderung nach Wiederaufnahme der wirtschaftlichen Jugendhilfe in das BSHG fallenzulassen.

223 Bundesvereinigung der Kommunalen Spitzenverbände an die Mitglieder des Ausschusses für Kommunalpolitik und öffentliche Fürsorge [...], 30.5.1960, mit Anlage „Stellungnahme zum Regierungsentwurf eines Bundessozialhilfegesetzes“ vom 31.5.1960, PA, Gesetzesmaterialien III/349 A3.

224 Vgl. Referat Bangert zu dem Entwurf eines BSHG [23.6.1960], ebenda.

225 Vgl. Referat Oel zu dem Entwurf eines BSHG [23.6. 1960], ebenda.

226 Referat Bangert [23.6.1960], ebenda. 
tung der laufenden Unterstützungen gerechnet. Auch die beiden Verbände der kreisangehörigen Städte bzw. Gemeinden machten sich die grundsätzliche Haltung des DLT zu eigen. ${ }^{227}$ Damit blieb auch weiterhin die pikante Situation bestehen, daß der sozialdemokratisch dominierte Städtetag dem Entwurf der CDU/ CSU-Regierung deutlich positiver gegenüberstand als der unionsnahe DLT.

In der Ablehnung der Regelungen zur freien Wohlfahrtspflege waren sich die Kommunalvertreter aber über alle Parteigrenzen hinweg völlig einig: Sie zeigten sich dabei bemüht, das gegenwärtige Verhältnis zu den freien Verbänden als „echte partnerschaftliche Zusammenarbeit“ 228 und die geplante Reglementierung als für diese Partnerschaft gefährlich darzustellen. Statt dessen wurde einhellig versichert, „daß kein öffentlicher Träger daran denkt, unsere freien Kräfte [...] an die Wand zu spielen, sondern daß die öffentlichen Träger im Gegenteil alles daran setzen werden, die freien Kräfte zu stützen" (Oel).229 Und Bangert versicherte durchaus glaubhaft, „die Landkreise denken gar nicht daran, [...] sich nunmehr auf Aufgabenbereiche zu stürzen, die bisher zum Wohle des der Hilfe Bedürftigen und zu beiderseitiger Zufriedenheit von der freien Wohlfahrtspflege betreut wurden." ${ }^{230}$ Angesichts des Regierungsentwurfs fürchteten die kommunalen Spitzenverbände aber, aus eigenen Tätigkeitsfeldern verdrängt, zur möglicherweise unwirtschaftlichen Subventionierung der freien Träger ohne jedes Mitspracherecht verpflichtet und damit zur bloßen „Verwaltungsstelle“ degradiert zu werden.231

Collmer versuchte seinerseits, die kommunalen Bedenken zu zerstreuen, indem er den umstrittenen $\ 86$ als Empfehlung an die Kommunen interpretierte, nicht aber als Funktionssperre zur Errichtung eigener kommunaler Einrichtungen. Im Mittelpunkt des BSHG stehe der hilfsbedürftige Mensch, es sei „kein Gesetz, das den Institutionen Ansprüche gibt, sondern ihnen Pflichten der Hilfe auferlegt“ ${ }^{2}{ }^{232}$ Nicht das Gesetz statuiere einen Vorrang in der Gestaltung der Hilfe, sondern der Hilfesuchende selbst entscheide über das Tätigwerden des öffentlichen oder des freien Trägers. So zumindest deutete Collmer das seiner Ansicht nach zentrale Wahlrecht, das er als notwendige Konsequenz der grundgesetzlich garantierten Personenwürde des Hilfesuchenden begriffen wissen wollte. Grundvoraussetzung für ein derartiges Funktionieren der Hilfeleistungen sei die Partnerschaft von öffentlichen und freien Trägern, die sich gegenseitig als gleichwertig und autonom anerkennen müßten. Allerdings hielt nun auch Collmer die freien Verbände für mehr als bisher gesetzlich schutzbedürftig, um ihre fürsorgerischen Aufgaben und damit „öffentliche Funktionen“ auch künftig wahrnehmen zu können, und recht-

227 Vgl. die Referate Possehl (DSB) bzw. Blumentrath (DGT) zu dem Entwurf eines BSHG [23.6.1960], ebenda.

228 Referat Oel [23.6.1960], ebenda.

229 Ders., ebenda.

230 Referat Bangert [23.6.1960], ebenda.

231 Johann Bangert, Subsidiarität, S.386; vgl. auch Bericht über die Sitzung des Fachausschusses I am 17./18.5.1960, ADW, HGSt, SP-S XXV 1: 110-1/2; Hoppe, Entwurf, S.355f.; ders., Verhältnis; Johann Bangert, Bundessozialhilfegesetz, S. 201ff.; Osterburg, Bundessozialhilfegesetz, S. 78f.

232 Referat Collmer [23.6.1960], PA, Gesetzesmaterialien III/349 A3; entsprechend in NDV 40 (1960), S. $372 \mathrm{ff}$. 
fertigte die von den Kommunen besonders heftig bekämpfte „Empfehlung an die Kommunalverwaltungen“ (Collmer) zur „angemessenen“ allgemeinen Förderung der freien Verbände in $\ 10$ Abs.3. Diese sei zwar in vielen Großstädten üblich, „aber weit seltener ist die Unterstützung der Verbände in den Landkreisen“.233 Nur sehr vorsichtig machte Collmer daher auf seine praktischen Bedenken etwa hinsichtlich der rechtlichen Folgen für Klage oder Haftung bei der Aufgabenübertragung an einen freien Träger aufmerksam.

Selbst wenn es Collmer gelungen wäre, die kommunalen Bedenken zu entkräften - die Stellungnahme Kleins für den DCV gab ihnen wieder neue Nahrung: Das Gesetz gewährleiste nicht „das so oft mißverstandene partnerschaftliche Verhältnis [...] in der Weise, daß behördlicher und freier Raum in gleicher Weise zu sozialer Funktion berufen sind“, sondern den Vorrang der freien Wohlfahrtspflege, die allein zur Erfüllung der gesetzlichen Individualhilfe befähigt sei. ${ }^{234}$ Mehr denn je war Klein dabei bemüht, diesen Vorrang primär aus dem Grundgesetz zu begründen, das der Gesellschaftsfunktion (der freien Verbände) einen Vorrang vor der Staatsfunktion (der Kommunen) einräume und allen, also auch den nichtkonfessionellen Verbänden zugute komme. Der Caritas-Justitiar würdigte daher den Gesetzentwurf als „bedeutsame Konkretisierung unseres Sozialstaates“235, meldete jedoch noch weitere Änderungswünsche an: Eine Verstärkung des Wahlrechts zur Muß-Bestimmung, Hilfe nur auf Antrag, am liebsten schließlich die Beschränkung der öffentlichen Hilfe überhaupt auf Geldleistungen.

Demgegenüber stellte sich die Fürsorgeexpertin der AWO Margot Paazig in dieser Frage eindeutig auf die Seite der Kommunen und interpretierte die geplanten Paragraphen als Gefährdung von Rechtsanspruch und Wahlfreiheit. Die Regelung der Stellung der freien Wohlfahrtspflege war das herausragende Monitum der AWO-Vertreterin, denn wenn sie auch dem Entwurf insgesamt nur „eine Reihe fortschrittlicher Bestimmungen" bescheinigte, blieb ihre weitere Kritik insgesamt zurückhaltend. 236

Ende Juni befaßte sich auch der Sozialpolitische Ausschuß der CDU mit dem BSHG-Entwurf - es war das erste Mal seit mehr als fünf Jahren, daß im sozialpolitischen Fachgremium der Bundespartei die Fürsorgereform überhaupt in den Sitzungsprotokollen greifbar wurde.237 Hauptthema war auch hier die Stellung der freien Wohlfahrtspflege, deren Wirkungsbereich „vor allem gegenüber Bestrebungen in den Städten mit sozialdemokratischer Mehrheit gesichert werden“"

\section{Ebenda.}

234 Referat Klein [23.6.1960], PA, Gesetzesmaterialien III/349 A3.

235 Ebenda.

236 Referat Paazig [23.6.1960], ebenda. Paazig bedauerte zwar grundsätzlich, daß die Gewährung laufender Leistungen Aufgabe der Sozialhilfe bleibe, machte aber nur wenige substantielle Änderungsvorschläge: Regelung der Freiheitsentziehung im Strafrecht; Festlegung der Familienzuschläge bei den Einkommensgrenzen im Verhältnis zum Regelsatz; Aufrechterhaltung der Bestimmung über Fachkräfte.

237 Vgl. Protokoll der Sitzung des Sozialpolitischen Ausschusses am 27./28. 6. 1960; Lünendonk an Adenauer, 12.7.1960, ACDP, Bundesgeschäftsstelle, VII-004-559/2; zur vorhergehenden und weiteren Tätigkeit vgl. die Protokolle und Unterlagen der Sitzungen des Ausschusses in: ACDP, Bundesgeschäftsstelle, VII-004-090/2 und -564/2. 
müsse. 238 Ein kleiner „Unterausschuß Bundessozialhilfegesetz“ sollte unter Leitung Collmers den Entwurf überprüfen. Tatsächlich aber waren neue Impulse hier kaum mehr zu erwarten, sondern vor allem eine Abgleichung mit der Linie der Bundestagsfraktion zu erreichen, wofür schon die Mitglieder des Unterausschusses - u.a. Niggemeyer, Willeke und der Geschäftsführer des Arbeitskreises IV der Fraktion, Friedrich Kühn - garantierten, und so stellte der Ausschuß seine Arbeit nach einer Sitzung Anfang November bereits wieder ein. 239

Nach der parlamentarischen Sommerpause begann der Bundestagsausschuß für Kommunalpolitik und öffentliche Fürsorge am 6. Oktober 1960 endlich mit der ersten Beratung des Entwurfs. ${ }^{240}$ In dieser ersten Phase von insgesamt zwölf Sitzungen bis Mitte Dezember wurden noch keine wesentlichen Änderungsanträge der Opposition gestellt; sie war gekennzeichnet durch eine im großen und ganzen parteiübergreifend positive Einschätzung des Regierungsentwurfs und der Vorschläge des Bundesrates, soweit sie die Stellung des Hilfsbedürftigen verbesserten. Das galt insbesondere für die Erhöhung der allgemeinen Einkommensgrenze sowie für die Hilfe für Blinde, deren Verbandsvertreter zu den wenigen überhaupt geladenen Sachverständigen gehörte. ${ }^{241}$ Im Gegensatz zum Bundesrat hielten es die Ausschußmitglieder allerdings für unerläßlich, die Gefährdetenhilfe im Gesetz wirksam, d.h. einschließlich der Möglichkeit zur Freiheitsentziehung zu regeln. ${ }^{242}$ Bei der letzten Sitzung im Dezember beschloß der Ausschuß, mit der zweiten Lesung des Entwurfs erst im Februar 1961 zu beginnen, um genügend Zeit für die Beratung in den zuständigen Gremien der Fraktionen und Parteien zur Verfügung zu haben; außerdem sollte die Sozialabteilung eine genaue Aufstellung über die Mehrkosten bei Erhöhung der Einkommensgrenzen und deren Auswirkung auf einzelne Berufsgruppen erarbeiten. ${ }^{243}$ Duntze fürchtete allerdings, daß diese großzügige Terminplanung die Verabschiedung in der laufenden Legislaturperiode doch noch verhindern könnte, zumal er mit der Anrufung des Vermittlungsausschusses rechnete; er drängte daher Willeke, mit der zweiten Lesung bereits im Januar zu beginnen, und fand auch die Zustimmung Maria Niggemeyers. ${ }^{244}$

Abgesehen von den leidvollen Erfahrungen Duntzes mit den Verzögerungen infolge der Jugendhilfereform war auch das Interesse der gesamten Regierung an einer Verabschiedung dieses großen Sozialgesetzes vor den Bundestagswahlen Grund für die Ungeduld. ${ }^{245}$ Zwar waren mit der Reform des Rentenrechts für

238 Vermerk Gottschick, 27.6.1960, BAK, B 106/29653a.

239 Vgl. Collmer an Kühn, 5.10.1960 und 2.11.1960, ACDP, Bundesgeschäftsstelle, VII004-106/1.

240 Vgl. Kurzprotokoll Kommunalpolitischer Ausschuß, 6.10.1960, PA, Gesetzesmaterialien III/349 A 1.

$241 \mathrm{Vgl}$. Kurzprotokolle Kommunalpolitischer Ausschuß, 27.10. und 1.12.1960, ebenda.

242 Vgl. Kurzprotokoll Kommunalpolitischer Ausschuß, 1. 12.1960, ebenda.

243 Vgl. Kurzprotokolle Kommunalpolitischer Ausschuß, 15.12.1960 und 19.1.1961, PA, Gesetzesmaterialien III/349 A1 bzw. A2.

244 Vgl. Duntze an Willeke, 27.12.1960; Niggemeyer an Duntze, 31.12.1960, mit Glosse Duntzes vom 3.1.1961, BAK, B 106/20654.

245 Vgl. BldW 107 (1960), S. 305. 
Flüchtlinge und Vertriebene, dem Handwerkerversicherungsgesetz und der Neuordnung des Kriegsopferrechts auch 1960 wichtige sozialpolitische Neuerungen eingeführt worden, doch die groß angelegte Reform der Krankenversicherung drohte zu scheitern und die geplante umfassende Neuregelung der Jugendhilfe war bereits im Herbst zur Novelle des RJWG geschrumpft. Auf ihrem Parteitag Ende November 1960 in Hannover hatte die SPD daher auch die Bundesregierung der sozialpolitischen Tatenlosigkeit geziehen und erklärt, anders als von der CDU verkündet, seien die „Grenzen des sozialen Rechtsstaates [...] nicht erreicht“. ${ }^{246}$ Adenauer mahnte daraufhin die Fraktion zu größtmöglicher Kraftanstrengung und disziplinierter Ausschußarbeit, zur Not müsse man eben „in der Zeit, die uns noch verbleibt, rücksichtslos von unserer Mehrheit Gebrauch machen“ ${ }^{247}$ Tatsächlich einigte man sich im Bundestagsausschuß nach anfänglichen Protesten von seiten der SPD und FDP darauf, bereits Mitte Januar mit der zweiten Lesung, und zwar der unproblematischen Bestimmungen, fortzufahren. ${ }^{248}$

Auf dieser Sitzung berichtete Gottschick über die Ergebnisse eines Verwaltungsplanspiels, mit dem der Regierungsentwurf in Nordrhein-Westfalen und Hamburg getestet worden war. Zum ersten Mal nämlich war ein derart umfassendes Gesetz im Stadium des Regierungsentwurfs in der Praxis "durchgespielt“ worden. ${ }^{249}$ Die Idee, ein noch nicht verabschiedetes Gesetz wie bei der „Erprobung einer neuen Flugzeugkonstruktion im Windkanal“250 in der Verwaltung vorab zu testen, stammte von dem Düsseldorfer Verwaltungsfachmann Udo Klausa. ${ }^{251}$ Auf diese Weise sollten erst in der Praxis erkennbare unerwünschte Effekte oder Gesetzeslücken ermittelt und entsprechende Verbesserungsvorschläge erarbeitet werden, um aufwendige Gesetzesänderungen, komplizierte Durchführungsbestimmungen oder teure Gerichtsverfahren bereits im Vorfeld zu verhindern. Im Frühling 1959 konnte Klausa und mit ihm das nordrhein-westfälische Sozialministerium zunächst den zuständigen Arbeitskreis der Länderinnenminister, dann auch die kommunalen Spitzenverbände und schließlich die Sozialabteilung für dieses Vorhaben gewinnen. ${ }^{252}$ Nach gründlicher Vorbereitung begann die

246 Entschließung zur Sozialpolitik des SPD-Parteitags am 21.-25.11.1960, in: Richter, Sozialreform, Bd. 6 G II.

247 Protokoll der Fraktionssitzung am 10.1.1961, in: CDU/CSU-Fraktion 1957-1961, S.739.

248 Vgl. Kurzprotokoll Kommunalpolitischer Ausschuß, 19.1.1960, PA, Gesetzesmaterialien III/349 A2. Könen wollte vermutlich erst die abschließenden Beratungen im AWOFachausschuß am 20.1.1961 abwarten; vgl. Protokolle der Sitzungen des Fachausschusses „Wohlfahrtspflege und Sozialpolitik“ am 9.12.1960 und 20.1.1961, AdsD, SPDBTF 3. Wp., 136.

$249 \mathrm{Vgl}$. ausführlich, auch zum folgenden, Nelles, Bundessozialhilfegesetz.

250 Udo Klausa, zitiert nach ebenda, S. 73.

251 Vgl. u.a. Klausa, Verwaltungsplanspiel. Klausa war Direktor des Landschaftsverbands Rheinland.

252 Vgl. auch Unterabteilung I C an Abteilung V, 23.5.1959, BAK, B 106/20644; Klausa an den Nordrhein-Westfälischen Städtetag etc., 21.7.1959; Vermerk Oel, 24. 8.1959, LAB, B Rep. 142-9, 1284, Beiheft „Verwaltungsplanspiel“; dort auch die weiteren einschlägigen Unterlagen des DST. 
eigentliche Spielphase dann mit Verabschiedung des Regierungsentwurfs 253 : Dabei war für den Erfolg des Experiments von entscheidender Bedeutung, daß der Bundestagsausschuß sich bereit erklärte, etwaige Ergebnisse bei der zweiten Lesung des BSHG-Entwurfs einzubeziehen. Nachdem in Nordrhein-Westfalen 14 kreisfreie Städte, 10 Landkreise und die beiden Landschaftsverbände 48 konstruierte Fälle bearbeitet und auch in Hamburg zwei Sozialämter die Bestimmungen getestet hatten, lagen die Ergebnisse kurz vor Weihnachten 1960 vor. ${ }^{254} \mathrm{Ham}-$ burg hatte 20, Nordrhein-Westfalen 36 z.T. ähnliche, vielfach nur formale Änderungsvorschläge erarbeitet - die lange Vorbereitungszeit des Entwurfs machte sich also bezahlt. Der Bundestagsausschuß übernahm neben zahlreichen technischen Details vor allem solche Vorschläge, die das Zusammentreffen mehrerer Voraussetzungstatbestände zugunsten der Hilfsbedürftigen klarer regelten, weitere aus der Praxis begründete Wünsche nach Leistungsverbesserungen, etwa nach Einbeziehung aller geistig Behinderten in die Eingliederungshilfe, hingegen nicht. 255 Die auf manchen Seiten befürchtete Präjudizierung der politischen Entscheidung ${ }^{256}$ durch das Verwaltungsplanspiel war also nicht eingetreten.

In der folgenden Sitzung Ende Januar äußerte sich endlich auch Muthesius als Sachverständiger und Vertreter des DV, nachdem die intensiven Beratungen der einzelnen Fachausschüsse abgeschlossen und auch mit Gottschick abgestimmt worden waren. ${ }^{257}$ Anders als beim ersten Referentenentwurf im Herbst 1958 hatte jetzt der Fachausschuß I, dem auch Niggemeyer und Könen angehörten, die Federführung übernommen mit dem Ergebnis, daß weiterreichende Wünsche der übrigen Fachausschüsse für ihr jeweiliges Spezialgebiet, etwa bei der Hauspflege, zum Teil deutlich zurückgeschraubt worden waren. In anderen lange strittigen Fragen hingegen fiel die offizielle DV-Position aufgrund der Mehrheitsverhältnisse im Fachausschuß überraschend eindeutig, und zwar zuungunsten gerade der Wünsche aus den Landkreisen aus: Die Kostenersatzpflicht sollte weiter gemil-

253 Vgl. Vermerk Referat V 1, 28.3.1960, BAK, B 106/20031; Niederschrift über die Sitzung des Unterausschusses „Verwaltungsvereinfachung“ des Ausschusses für Innere Angelegenheiten des Bundesrats am 29.3.1960, BAK, B 106/20024.

254 Vgl. Sozialbehörde Hamburg: Ergebnis eines Verwaltungsplanspiels, 28.11.1960; Arbeits- und Sozialminister von Nordrhein-Westfalen: Bemerkungen und Vorschläge [...] auf Grund der Ergebnisse des Verwaltungsplanspiels, 20.1./2.2.1961, PA, Gesetzesmaterialien III/349 A4; Vermerke Referat V 4 vom 27.12.1960, BAK, B 106/20031, und 9.1.1960, BAK, B 106/20024, betr. Ergebnisse eines vom Land Nordrhein-Westfalen durchgeführten Verwaltungsplanspiels.

255 Vgl. Kurzprotokoll Kommunalpolitischer Ausschuß, 23.2.1960, PA, Gesetzesmaterialien III/349 A2; Nelles, Bundessozialhilfegesetz, S. 78.

256 Vgl. Niederschrift über die Sitzung des Unterausschusses „Verwaltungsvereinfachung“ des Ausschusses für Innere Angelegenheiten des Bundesrats am 29.3.1960, BAK, B $106 / 20024$.

257 Vgl. Kurzprotokoll Kommunalpolitischer Ausschuß, 25.1.1960, PA, Gesetzesmaterialien III/349 A2; Vorschläge des DV zum Entwurf eines Bundessozialhilfegesetzes o.D., ebenda A3. Zu den Beratungen des Fachausschusses I vgl. die Berichte über dessen Sitzungen am 17./18.5., 6./7.7. und 27.9.1960, mit Anlagen, ADW, HGSt, SP-S XXV 1: 110-1/2; ferner Hoppe, Entwurf; Wehlitz, Rangfolge; Kobus, Träger; NDV 40 (1960), S. 290ff.; 41 (1961), S. 32; Gottschick an DV, 7.11.1960, BAK, B 106/9787; Pense an Abteilung V, 25.11.1960, BAK, B 106/9687. 
dert ${ }^{258}$, die Altenhilfe noch ausgebaut und die vorbeugende Gesundheitshilfe nicht zur Kann-Bestimmung reduziert werden. Muthesius selbst sprach sich abweichend von der offiziellen DV-Vorlage außerdem für ein festes Pflegegeld für Schwerbeschädigte aus. ${ }^{259}$ Bei der Blindenhilfe allerdings, vor allem aber in der Subsidiaritätsfrage war kein Konsens erzielt worden. Im Gegenteil: Auf der Tagung des DV-Hauptausschusses am 3. November 1960 wurden die unter dem Dach des DV versammelten Gegensätze wieder öffentlich deutlich. ${ }^{260}$ Die Hoffnung, über den DV diesen Konflikt aus dem Bundestagsausschuß heraushalten zu können, hatte sich damit nicht erfüllt. Statt dessen beschloß der Bundestagsausschuß, dieses Problem bis zum Abschluß der übrigen Beratungen zu vertagen. ${ }^{261}$

Doch die Subsidiaritätsfrage war nicht die einzige, die im Ausschuß für Konflikte sorgte und das Ende der Beratungen weiter verzögerte. Die Phase der zweiten Lesung mit insgesamt 11 Sitzungen war gekennzeichnet durch das Bestreben der SPD-Mitglieder, weitere Verbesserungen für die künftigen Sozialhilfeempfänger durchzusetzen, während die christdemokratischen Abgeordneten ebenso wie der FDP-Vertreter meist bremsend wirkten. Neben Willekes grundsätzlich starker kommunaler Affinität zeigte auch Maria Niggemeyer - mit Ausnahme der Subsidiaritätsfrage - immer wieder Verständnis für die finanziellen Bedenken der kommunalen Träger. Dabei spielte die Rücksichtnahme auf die bayerische Schwesterpartei eine entscheidende Rolle: Die CSU-Vertreter im Ausschuß exponierten sich nämlich zunehmend im Interesse der bekanntermaßen reformfeindlichen kommunalen Spitzenverbände Bayerns. Sollte nicht ausgerechnet bei diesem eigentlich so wenig strittigen Gesetzentwurf die Fraktionsgemeinschaft der Union Schaden nehmen, durfte der begrenzte Reformwille der süddeutschen Kommunen nicht überstrapaziert werden. ${ }^{262}$

Das zeigte sich bereits bei den Beratungen über die Hilfe zum Lebensunterhalt: Nachdem der Allgemeine Teil des BSHG (ohne die Paragraphen zur freien Wohlfahrtspflege) noch am 19. Januar 1961 mit kleineren Änderungen zügig und einvernehmlich vom Ausschuß verabschiedet worden war ${ }^{263}$, kam es bei den Bestimmungen über die vorgesehene Regelsatzverordnung zu keinem Konsens zwischen den Parteien. Laut $\$ 20$ Abs. 2 des Regierungsentwurfs sollte die mit der Zustim-

258 An der diesbezüglich entscheidenden Sitzung hatte Bangert gar nicht teilgenommen; vgl. Bericht über die Sitzung des Fachausschusses I am 6./7.7.1960, Anlage 1, ADW, HGSt, SP-S XXV 1: 110-1/2.

259 Vgl. Kurzprotokoll Kommunalpolitischer Ausschuß, 25.1.1961, PA, Gesetzesmaterialien III/349 A2.

260 Vgl. NDV 41 (1961), S. $1 \mathrm{ff}$.

261 Vgl. Kurzprotokolle Kommunalpolitischer Ausschuß, 19.1. und 3.3.1961, PA, Gesetzesmaterialien III/349 A2.

262 Die bayerischen Verbände wünschten die Beibehaltung des anderthalbfachen Regelsatzes als allgemeine Einkommensgrenze, die Streichung der Gefährdetenhilfe und der Vorschriften über Fachkräfte, die vorbeugende Gesundheitshilfe nur als Kann-Leistung und keine Änderung der geplanten Regelung zur Rückerstattungspflicht; vgl. Bayerischer Städteverband und Landkreisverband Bayern an DST und DLT, 20.6.1960, LAB, B Rep. 142-9, 1285; Osterburg, Bundessozialhilfegesetz.

263 Vgl. Kurzprotokoll Kommunalpolitischer Ausschuß, 19.1.1961, PA, Gesetzesmaterialien III/349 A2. 
mung des Bundesrates zu erlassende Verordnung neben Inhalt und Aufbau der Regelsätze auch deren Verhältnis zum Arbeitseinkommen regeln. Die zentrale, zumindest von seiten des DGB nach wie vor thematisierte Frage der Bemessungsgrundlage für die Regelsätze und deren mögliche Dynamisierung wurde von den SPD-Vertretern im Ausschuß nicht mehr angeschnitten ${ }^{264}$; ebensowenig wurde nach Wegen für eine stärkere Standardisierung der Hilfe zum Lebensunterhalt gesucht, sondern die Möglichkeit einer Festsetzung der Regelsätze durch die Kommunen selbst auch weiterhin ermöglicht. ${ }^{265}$ Diese Zurückhaltung der SPD lag neben grundsätzlichen Vorbehalten auch sozialdemokratischer Fürsorgefachleute wie Heinz Keese möglicherweise auch daran, daß seit Mai 1960 im DV-Arbeitskreis abermals das Warenkorb-Modell überarbeitet wurde und dabei auch auf den gestiegenen allgemeinen Lebensstandard Bezug genommen werden sollte. ${ }^{266}$ Die sozialdemokratischen Ausschußmitglieder befürchteten allerdings, daß über den Passus zum Arbeitseinkommen die unrühmliche, 1953/1955 verabschiedete Auffanggrenze durch die Hintertür Eingang in die neue Sozialhilfe finden könne. ${ }^{267}$ Duntze und Gottschick argumentierten allerdings, daß mit dieser Bestimmung wie bisher nur allgemein bei der Festsetzung der Regelsätze das Arbeitseinkommen zu berücksichtigen sei, nicht aber im konkreten Einzelfall wieder die volle Bedarfsdeckung versagt werden könne, bloß weil sie über örtlichen Niedriglöhnen lag. ${ }^{268}$ Die Berücksichtigung des Arbeitseinkommens entsprach vor allem auch Wünschen von seiten des Bundesarbeitsministeriums, wo man sonst unerwünschte Rückwirkungen auf die Arbeitslosenhilfe befürchtete. ${ }^{269}$ Nachdem der Ausschuß noch in der ersten Lesung auf Antrag Könens den Passus gestrichen

264 Der DGB hatte in seiner Stellungnahme zum BSHG-Entwurf vom 4. 5.1960, PA, Gesetzesmaterialien III/349 A3, gefordert, bei der Festsetzung der Regelsätze auch die jeweilige Rentenbemessungsgrundlage heranzuziehen, die anhand der durchschnittlichen Arbeitnehmereinkommen berechnete wurde; außerdem sollten im BSHG bestimmte prozentuale Mindestsätze vorgeschrieben werden; vgl. auch Soziale Sicherheit 9 (1960), S. 182.

265 Vgl. Schriftlicher Bericht des Ausschusses für Kommunalpolitik und öffentliche Fürsorge, S. 5, BT, 3. Wp. 1957, Anlagen, Bd. 74, Drs. 2673.

266 Vgl. Niederschriften über die Tagungen der leitenden Fürsorgereferenten der Länder am 4./5.5.1960, ADW, ZB 7052, und 27./28. 4.1961, BAK, B 106/9697; Bericht über die Sitzung des Arbeitskreises „Aufbau der Richtsätze“ am 16.5.1960, ADW, HGSt 7025; NDV 40 (1960), S. 290; 41 (1961), S. 66.

267 Vgl. Kurzprotokoll Kommunalpolitischer Ausschuß, 20.10.1960, PA, Gesetzesmaterialien III/349 A1.

268 Vgl. ebenda sowie 9.2.1961, ebenda, A2. So auch die Mehrheitsmeinung bei den Länderfürsorgereferenten, vgl. Niederschrift über deren Besprechung am 27./28.4.1961 sowie Vermerk Referat V4 vom 2.5.1961, BAK, B 106/9697, und im Fachausschuß I des DV, vgl. Niederschrift über dessen Sitzung am 17./18.5.1960, Anlage 4, ADW, HGSt, SP-S XXV 1: 110-1/2. Selbst Bangert hatte vor dem Bundestagsausschuß erklärt, auch die Landkreise wollten keine örtliche Auffanggrenze. „Trotzdem wird man es uns nicht verwehren dürfen, daß wir dann warnend unsere Stimme erheben, wenn durch unberechtigte, oft nur politisch bedingte Richtsatzerhöhungen die ganze Sozialstruktur meist überwiegend ländlicher Gebiete gestört wird“; Referat Bangert [23.6.1960], PA, Gesetzesmaterialien III/349 A3.

269 Vgl. Kurzprotokoll Kommunalpolitischer Ausschuß, 20.10.1960, PA, Gesetzesmaterialien III/349 A1. 
hatte, wurde er mit der Ausschußmehrheit der Union und der Stimme der FDP bei fünf Gegenstimmen in der zweiten Lesung wieder eingefügt. ${ }^{270}$ Gottschick rechnete - wie sich zeigen sollte, zu Recht - damit, daß die SPD die Frage noch vor das Bundestagsplenum bringen werde. ${ }^{271}$ Ansonsten sorgte der Ausschuß stets einstimmig - bei der Hilfe zum Lebensunterhalt vor allem für formalrechtliche Klarstellungen und einzelne kleinere Verbesserungen ${ }^{272}$, verpflichtete die Sozialhilfeträger auf das Ziel, Nichtseßhafte seßhaft zu machen, und übernahm die vom Bundesrat vorgeschlagene Ergänzung über den besonderen Bedarf von Kindern und Jugendlichen. ${ }^{273}$

Abgesehen von diesen Akzentverschiebungen war der Ausschuß also nicht gewillt, bei der traditionellen Hilfe zum Lebensunterhalt neue Wege einzuschlagen. Das bewies auch die Behandlung der Rückzahlungspflicht. Der Bundesrat hatte, wie ein Jahr zuvor die für das Wohlfahrtswesen zuständigen Minister der Länder, empfohlen, auch hier nur in „offensichtlich unbilligen“ Fällen oder bei vorsätzlich oder grob fahrlässig herbeigeführter Hilfsbedürftigkeit Kostenersatz zu verlangen. Weder „der materielle noch der psychologische Erfolg der bisherigen Bestimmungen" rechtfertigten die darüber hinausgehenden Vorschriften des Entwurfs $(\$ 85)$, wonach eine Familie mit einem Kind ersatzpflichtig war, wenn ihr später ein monatliches Nettoeinkommen von mehr als 660 DM oder ein Vermögen von 6000 DM, dem Anschaffungspreis für ein Auto, zur Verfügung stand, sofern dieses Vermögen nicht ohnehin geschützt war. Für ebenso wenig effektiv hielt der Bundesrat die Ersatzpflicht des Erben aus dem Nachlaß und daß der Anspruch auf Erstattung erst nach vier Jahren erlöschen sollte. ${ }^{274}$ Die Bundesregierung lehnte diese Änderung ab mit der formalen Begründung, daß sie nicht justitiabel sei. ${ }^{275}$ Tatsächlich waren die alten Fronten unverändert: Der Fachausschuß I des DV stimmte ebenso wie die AWO der Linie des Bundesrates zu; der DST unterstützte weitgehend den Regierungsentwurf. ${ }^{276}$ Demgegenüber wünschten der

270 Vgl. ebenda; Kurzprotokoll Kommunalpolitischer Ausschuß, 9.2.1961, ebenda A2.

271 Vgl. Ministervorlage Referat V 4 vom 29. 4.1961, BAK, B 106/20653b.

272 Der Ausschuß beschloß u.a., daß der Mehrbedarf nicht nur für Mütter, sondern alle Personen gelten sollte, die für mindestens zwei jüngere Kinder sorgten, daß der Sozialhilfeträger gegebenenfalls auch Beiträge für eine Sterbegeldversicherung sowie für Rentenantragsteller zur Krankenversicherung übernehmen und die Zahlung eines Taschengeldes in Anstalten großzügiger gehandhabt werden sollte; vgl. Kurzprotokoll Kommunalpolitischer Ausschuß, 9.2.1961, PA, Gesetzesmaterialien III/349 A2.

273 Vgl. Kurzprotokolle Kommunalpolitischer Ausschuß, 19.10.1960, PA, Gesetzesmaterialien III/349 A1, sowie 19.1.1961, ebenda, A2. Die bei der Verabschiedung des FÄG einst so heftig umkämpfte Frage des Mehrbedarfs für Kriegsopfer wurde jetzt im Bundesversorgungsgesetz geregelt.

274 Vgl. Stellungnahme des Bundesrates zum BSHG-Regierungsentwurf, S. 75f.; Zitat S. 76, BT, 3. Wp. 1957, Anlagen, Bd.67, Drs. 1799. Laut $\$ 81$ Abs. 2 des Entwurfs grundsätzlich nicht einzusetzen war allerdings Vermögen zum Aufbau oder zur Sicherung einer Lebensgrundlage, zur Gründung eines Hausstandes, ein kleines Hausgrundstück, angemessener Hausrat oder ein Teil von Familien- und Erbstücken u.ä.

275 Vgl. Auffassung der Bundesregierung zur Stellungnahme des Bundesrates, S. 86, ebenda.

276 Bericht über die Sitzung des DV-Fachausschusses I am 6./7.7.1960, ADW, HGSt, SP-S XXV 1: 110-1/2; Vorschläge des DV zum Regierungsentwurf [o.D.]; Referate Paazig und Oel vor dem Bundestagsausschuß [23.6.1960], PA, Gesetzesmaterialien III/349 A3. 
DLT, der bayerische Städteverband und die beiden Spitzenverbände der kreisangehörigen Städte und Gemeinden nach wie vor den umgekehrten Weg: Beibehaltung des Ersatzes „als sozialethische Schranke“ mit den vorgesehenen Ausnahmen; bemerkenswerterweise sahen aber auch diese Kommunalvertreter genau das durch den Regierungsentwurf gewährleistet. ${ }^{277}$

Auch im Bundestagsausschuß verliefen die Grenzen zunächst quer zu den Parteien: Während Maria Niggemeyer und selbst Willeke von der Union zunächst mit dem Bundesratsvorschlag sympathisierten, machte sich der Sozialdemokrat und ehemalige Kreisdirektor Kurt Schröder für die Ersatzpflicht stark. ${ }^{278}$ Insgesamt dominierte im Ausschuß parteiübergreifend die Tendenz, die Regelungen des Regierungsentwurfs beizubehalten. Das schloß Modifikationen im einzelnen aber nicht aus: So waren sich die Ausschußmitglieder aller Fraktionen einig, daß auch Unterhaltspflichtige, die Hilfeleistungen für ihre Angehörigen verschuldeten, ersatzpflichtig sein sollten. ${ }^{279}$ Eine weitere Verschärfung allerdings kam nur gegen die Stimmen der SPD zustande: Spitzmüller forderte, ,aus psychologischen Gründen" den Vermögensfreibetrag zu halbieren und so zu stärkerer Selbsthilfe zu animieren 280 ; die Mehrheit aus Union und FDP stimmte diesem Antrag schließlich zu, zumal, so Niggemeyer, die Höhe der Vermögensgrenze ohnehin „nach den tatsächlichen Verhältnissen [...] in den meisten Fällen unerheblich sein werde“. ${ }^{281}$ Ein wesentlicher Grund für die Zustimmung der CDUAbgeordneten dürfte auch hier die Rücksichtnahme auf die CSU - wie die süddeutschen Länder überhaupt - und die von ihr repräsentierten ländlichen Interessen gewesen sein, hatte doch der CSU-Abgeordnete Spies sogar beantragt, die Regelung des Vermögensschutzes und der Ersatzpflicht ganz den Ländern zu überlassen. ${ }^{282}$

Könen bezweifelte, ob überhaupt noch - wie in der Begründung des Regierungsentwurfs - von einer grundsätzlichen Abschaffung der Kostenersatzpflicht gesprochen werden könne. ${ }^{283}$ Tatsächlich aber war die unmittelbare materielle Bedeutung der Ersatzpflicht auch nach diesen Verschärfungen nur gering, und die Rückflüsse nach $\ 92$ BSHG, wie er dann unverändert lautete, blieben prozentual

277 Vgl. die Referate Bangert, Possehl und Blumentrath vor dem Bundestagsausschuß [23.6. 1960], ebenda, Zitat: Bangert; Bayerischer Städteverband an DST, 9.5.1960, LAB, B Rep. 142-9, 1284; Osterburg, Bundessozialhilfegesetz, S. 79.

278 Vgl. Kurzprotokoll Kommunalpolitischer Ausschuß, 2.12.1960, PA, Gesetzesmaterialien III/349 A1.

279 Vgl. ebenda, sowie Kurzprotokoll, 12.4.1961, ebenda, A2.

280 Kurzprotokoll Kommunalpolitischer Ausschuß, 3.3.1961, ebenda.

281 Kurzprotokoll Kommunalpolitischer Ausschuß, 12.4.1961, ebenda; vgl. ferner Kurzprotokoll, 13.4.1961, ebenda.

282 Vgl. Kurzprotokoll Kommunalpolitischer Ausschuß, 12.4.1961, ebenda. Die Länderreferenten der „süddeutschen Länder“ (neben Bayern und Baden-Württemberg vermutlich Rheinland-Pfalz) sprachen sich gegen einen Verzicht auf die Kostenerstattung aus, die die Mehrheit der Ländervertreter favorisierte; vgl. Niederschrift über die Dienstbesprechung der Leitenden Fürsorgereferenten am 27./28. 4.1961; Vermerk Referat V 4, 2.5.1961, BAK, B 106/9697.

283 Vgl. ebenda; Begründung zum BSHG-Entwurf, S. 35, BT, 3. Wp. 1957, Anlagen, Bd.67, Drs. 1799. 
im einstelligen Bereich. ${ }^{284}$ Entscheidender war, daß die Unionsmehrheit im Bundestagsausschuß, die etwa beim Pflegegeld für Schwerbehinderte eine Verteuerung der Sozialhilfe nicht scheute, aus parteiinternen Gründen in der ideologischen Frage der Rückerstattungspflicht nicht den letzten Schritt wagte und dafür selbst Gründe der Verwaltungspragmatik nicht gelten ließ.

Nicht konzessionsbereit hingegen war die Mehrheit der Unionsvertreter im Bundestagsausschuß bei der allgemeinen Einkommensgrenze für die Hilfe in besonderen Lebenslagen. Die Bundesregierung, so Duntze vor dem Bundestagsausschuß, habe der vom Bundesrat gewünschten Erhöhung auf den doppelten Regelsatz „mit Freuden zugestimmt“ ${ }^{285}$ Demgegenüber stellte sich die CSU-Landesgruppe auf die Seite der bayerischen kommunalen Spitzenverbände und des DLT, die die Rückkehr zum anderthalbfachen Regelsatz mit der vertrauten Begründung forderten, auf dem Lande würde sonst in einen Bevölkerungsteil vorgedrungen, „der bisher gar nicht daran gedacht hat, die Hilfe der Öffentlichkeit in Anspruch zu nehmen". ${ }^{286}$ Diese Meinung erhielt Auftrieb auch durch die Tatsache, daß seit Herbst 1959/Winter 1960 in allen Bundesländern die Richtsätze um 3 bis 8 DM angehoben worden waren. ${ }^{287}$ Vor allem aber entsprachen die CSU-Forderungen offenbar auch der dominierenden Meinung im Arbeitskreis IV der Bundestagsfraktion ${ }^{288}$, was die Position der Befürworter des zweifachen Richtsatzes wie Maria Niggemeyer nicht gerade erleichterte.

Demgegenüber übte Heinz Keese vor dem wieder aktivierten DV-Arbeitskreis "Aufbau der Richtsätze“ heftige Kritik am anderthalbfachen Regelsatz: Allein der genuine Lebensunterhalt umfasse sehr viel mehr, als durch die Richtsätze derzeit abgedeckt werde, etwa Kleidung, Heizung, Mehrbedarfe, Winterbeihilfen oder Pflegezulagen. Der Regelsatz und diese Bedürfnisse nur für den reinen Lebensbedarf gerieten zusammengenommen "schon so sehr in die Nähe des eineinhalbfachen Regelsatzes, daß von dem Ziel, einen erweiterten Hilfsbedürftigkeitsbegriff zu schaffen, nicht mehr viel übrig bliebe“. ${ }^{289} \mathrm{Zwar}$ bestünde in der Praxis die Möglichkeit, dies durch eine niedrig angesetzte Beitragspflicht aus dem überschießenden Einkommen auszugleichen, doch eine „niedrige, eine schlechte Grenze wird nicht dadurch besser, daß man an die Großzügigkeit der ausführenden Stellen appelliert“. ${ }^{290}$ Ausführliche Berechnungen, die Duntze

284 Vgl. für die (vermutlich relativ großzügige) Praxis in Hannover Reinhold, Entwicklung.

285 Kurzprotokoll Kommunalpolitischer Ausschuß, 11.5.1960, PA, Gesetzesmaterialien III/349 A1.

286 Referat Bangert [23.6.1960], ebenda, A3; vgl. ferner Osterburg, Bundessozialhilfegesetz, S. 79f.; die Vermerke Referat V 4 o.D. [23.2.1961], BAK, B 106/20654, sowie vom 2.5.1961, BAK, B 106/9697.

287 Vgl. die Aufstellung bei Heisig, Armenpolitik, 1990, S. 721f.; ferner allgemein Heisig, Armenpolitik, 1995, S.171ff.

288 Vgl. Protokoll der Sitzung des Arbeitskreises IV am 28.2.1961, ACDP, CDU/CSUFraktion AK IV, VIII-005-106/1.

289 Vgl. Bericht über die Sitzung des Arbeitskreises „Aufbau der Richtsätze“ am 16.5.1960, ADW, HGSt 7025; Keeses Referat wurde veröffentlicht in: NDV 40 (1960), S. 276-280 (Zitat: S. 276).

290 NDV 40 (1960), S. 276. 
Mitte Dezember 1960 dem Bundestagsausschuß vorstellte, ergaben ohnehin, daß mit dem doppelten Regelsatz der Grundbetrag nur um durchschnittlich 37 DM erhöht und nicht in neue Einkommensgruppen vorgestoßen wurde, sondern nur Familien von Geringverdienern mit Kindern etwas eher in den Genuß der Hilfe in besonderen Lebenslagen kommen konnten; selbst einfache Beamte (Postschaffner, Amtsgehilfen) lagen mit ihren Netto-Gehältern in der Regel über der allgemeinen Einkommensgrenze und konnten allenfalls Tuberkulose-, Blindenoder stationäre Eingliederungshilfe erwarten. ${ }^{291}$ Die Behauptung der Leitartiklerin der „Frankfurter Allgemeinen Zeitung“, Heddy Neumeister, sämtliche Hilfen in besonderen Lebenslagen würden künftig Personen mit einem Bruttoeinkommen zwischen 600 und 800 DM zugute kommen, es werde also „nicht mehr und nicht weniger versucht, als das gesamte Kleinbürgertum bis hoch hinauf in den Mittelstand in die Fürsorge einzubeziehen “292, entbehrten damit ebenso der Grundlage wie die Befürchtung der CDU-Abgeordneten Margot Kalinke, künftig seien monatliche Sozialhilfeleistungen von 1000 DM nicht unwahrscheinlich. ${ }^{293}$

Die Mehrbelastungen durch die Erhöhung auf den doppelten Regelsatz veranschlagte das Bundesinnenministerium auf insgesamt 16,2 Mio. DM im Jahr. ${ }^{294}$ Hinzu kamen allerdings weitere mögliche jährliche Mehrkosten infolge anderer Verbesserungsvorschläge des Bundesrates ${ }^{295}$ (15,9 Mio. DM) und des Ausschusses selbst $^{296}$ (14,6 Mio. DM), so daß die Sozialhilfeträger gegenüber dem Regierungsentwurf insgesamt mit weiteren rund 47 Mio. DM jährlich zu rechnen hätten bei einem derzeitigen Gesamtvolumen der Fürsorge von 1,5 Mrd. DM pro Jahr. ${ }^{297}$ Mehr als die Hälfte dieser Mehrbelastungen würde allerdings auf die überörtlichen Träger entfallen. Als der CSU-Abgeordnete Spies daher wieder den anderthalbfachen Regelsatz als Grundbetrag für die allgemeine Einkommensgrenze forderte, wurde er mit den Stimmen auch aus den Reihen der Union abgewiesen, obwohl das der kurz zuvor bekräftigten Beschlußlage im Sozialpolitischen Ar-

291 Bei einem Grundbetrag in Höhe des doppelten Regelsatzes hatte jetzt z.B. ein Hilfsarbeiter in der Schuhindustrie (Netto-Monatslohn 285,50 DM) mit Ehefrau bereits ab dem ersten Kind Anspruch auf Hilfe, ein einfacher Angestellter ohne Berufsausbildung (Leistungsgruppe V: 379,47 monatliches Nettogehalt) ab dem zweiten und nicht - wie beim anderthalbfachen Regelsatz - erst ab dem vierten Kind; berechnet nach den Angaben des BMI betr. finanzielle Auswirkungen des BSHG, 2.1.1961, PA, Gesetzesmaterialien III/349 A3; vgl. ferner Kurzprotokoll Kommunalpolitischer Ausschuß, 15.12.1960, ebenda, A1; Gottschick an Niggemeyer, 8.3.1961, mit Anlage, BAK, B 106/9687.

292 Frankfurter Allgemeine Zeitung vom 30.1.1961.

293 Vgl. Gottschick an Kalinke, 6.3.1961, BAK, B 106/9687.

294 Vgl. Zusammenstellung des BMI betr. finanzielle Auswirkungen des BSHG, 2. 1.1961, PA, Gesetzesmaterialien III/349 A3.

295 Einbeziehung der Hilfe zur Pflege und der Hilfe zur Familien- und Hauspflege in die höhere allgemeine Einkommensgrenze nach $\$ 76$, Erhöhung der Einkommensgrenze für Blinde auf 1000 DM.

296 Erhöhung der Blindenhilfe; noch ohne festes Pflegegeld.

297 Vgl. Zusammenstellung des BMI betr. finanzielle Auswirkungen des BSHG, 2. 1.1961, PA, Gesetzesmaterialien III/349 A3. 
beitskreis der CDU/CSU widersprach. ${ }^{298} \mathrm{Da}$ immerhin der Bundesrat als Länderorgan selbst deren Erhöhung vorgeschlagen und die Bundesregierung dem auch zugestimmt hatte, schien eine erneute Verminderung durch die Regierungspartei schon aus politischen Gründen wenig opportun. ${ }^{299}$ Wie sich zeigen sollte, war die Frage der Einkommensgrenzen für die bayerische Schwesterpartei damit aber noch nicht vom Tisch.

Nachdem der BSHG-Entwurf damit im wesentlichen parteiübergreifend beschlossen bzw. einhellig geändert worden war, beschäftigte der Ausschuß sich am 13. und 14. April abschließend mit den Regelungen zur freien Wohlfahrtspflege. Bereits Anfang Dezember hatte Gottschick vermutet, daß es in dieser Frage im Ausschuß zu keiner Einigung und im Plenum des Bundestages zu einer Kampfabstimmung kommen werde. ${ }^{300}$ Dabei gab es im Rahmen des DV durchaus Bemühungen um einen Kompromiß: Im Novemberheft des NDV hatte jede Seite noch einmal ausführlich ihren Standpunkt dargelegt und dabei Franz Klein sich eindeutiger als bisher auf den Boden des Regierungsentwurfs gestellt und betont, daß der umstrittene $\mathbb{1} 10$ Abs. 3 eben nicht den von den Kommunen gefürchteten erzwingbaren Leistungsanspruch der freien Verbände, sondern nur eine allgemeine Unterstützungspflicht der Sozialhilfeträger begründe. ${ }^{301}$ Auch der DPW suchte den Konflikt zu entschärfen und erklärte, selbst $\ 86$ entspreche materiellrechtlich "weitgehend, vielleicht sogar völlig, dem geltenden Recht [...]. Denn es ist in der Geltungszeit der Reichsfürsorgepflichtverordnung den caritativen Organisationen jederzeit möglich gewesen, den Zustand des ,Vorhandenseins' einer Einrichtung herbeizuführen, ohne daß die öffentliche Fürsorge, auch wenn sie es gewollt hätte, dies hätte verhindern können, vom ,Ausbauen' ganz abgesehen“.302

Vor allem aber hatte Senatsdirektor Kurt Wehlitz (CDU) von der Berliner Sozialverwaltung auf der Hauptausschußsitzung des DV mit gut 500 Teilnehmern am 3./4. November 1960 eine für alle Seiten annehmbare Interpretation des Regierungsentwurfs versucht: Nach wiederholter Rücksprache mit dem ihm aus seiner ehemaligen Tätigkeit für die Innere Mission bekannten Collmer übernahm Wehlitz wesentliche Punkte von dessen Argumentation, indem er die Regelungen der $\mathbb{S} 8$ und 10 als notwendige Konsequenz der Wahlfreiheit des Hilfesuchenden deutete, ansonsten aber den appellativen Charakter von $\$ 10 \mathrm{Abs} .3$ betonte und den Vorrang der freien Träger bei Einzelmaßnahmen nach $\mathbb{1 0}$ Abs. 4 im Sinne

298 Vgl. Kurzprotokoll Kommunalpolitischer Ausschuß, 2.3.1961, PA, Gesetzesmaterialien III/349 A2; Protokoll der Sitzung des Arbeitskreises IV am 28.2.1961, ACDP, CDU/CSU-Fraktion AK IV, VIII-005-106/1; Ministervorlage Abteilungsleiter V vom 27.4.1961, BAK, B 106/9687; die Angaben über die Abstimmungsergebnisse stimmen allerdings nicht ganz überein. Vgl. ferner den Schriftlichen Bericht des Ausschusses für Kommunalpolitik und öffentliche Fürsorge, S. 8, 41f., BT, 3. Wp. 1957, Anlagen, Bd.74, Drs. 2673. Zur Haltung des DLT in dieser Frage vgl. Schröder an Krone, 28.4.1961, BAK, B 106/9687; Vermerk Referat V 4 vom 2.5.1961, BAK, B 106/9697.

299 Vgl. Ministervorlage Abteilungsleiter V vom 27.4.1961, BAK, B 106/9687.

300 Vgl. Gottschick an Wehlitz, 9.12.1960, ebenda.

301 Vgl. Franz Klein, Organisationsprinzip, S. 380; ferner Collmer, Wohlfahrtspflege; NDV 40 (1960), S. 376ff., 383ff.; Johann Bangert, Subsidiarität.

302 NDV 40 (1960), S. 385. 
einer eingeschränkten Leistungspflicht des Sozialhilfeträgers vor allem bei der persönlichen Hilfe interpretierte, aus der kein Wohlfahrtsverband etwa nachträglich Erstattungsansprüche für nicht gesetzlich vorgesehene Maßnahmen ableiten könne. ${ }^{303}$ Den Einrichtungsvorbehalt nach $\mathbb{8} 86$ allerdings hielt auch Wehlitz für zu weitgehend und forderte eine Streichung des Wortes „können“. ${ }^{304}$ Zwar dankten Gottschick und Collmer später dem Berliner Fürsorgefachmann für seine Bemühungen um eine Annäherung, doch schon die Stellungnahmen Niggemeyers und Könens und die Aussprache im Hauptausschuß machten deutlich, daß mit einem Kompromiß kaum zu rechnen war. ${ }^{305}$ Für zusätzliche Verwirrung sorgte, daß Pastor Ohl aus seiner Skepsis gegenüber den geplanten Bestimmungen keinen Hehl machte, woraufhin Collmer nicht nur die anwesenden Caritas-Vertreter, sondern auch evangelische Teilnehmer beruhigen und der Unterstützung der evangelischen Kirche für den Regierungsentwurf versichern mußte. ${ }^{306} \mathrm{Im}$ DVVorstand gab es zwar Anfang 1961 noch Überlegungen für die Wiederbelebung von „Religionsgesprächen“, wie sie bereits in den zwanziger Jahren im DV von Polligkeit initiiert worden waren ${ }^{307}$, doch letztendlich fand der DV hier offiziell zu keiner einheitlichen Stellungnahme. ${ }^{308}$ Muthesius selbst blieb zwar bei seiner Auffassung, daß die Gemeinde planende Entscheidungsinstanz bleiben müsse, ging aber davon aus, daß sich auf örtlicher Ebene die Dinge ohnehin einvernehmlich regeln ließen und die allseitige „Dramatisierung die Frage des Zusammenwirkens erschwere". 309

Tatsächlich war für einen Kompromiß zwischen den Bundestagsparteien politisch zu dieser Zeit kaum noch Raum: Das lag am mittlerweile angelaufenen Bundestagswahlkampf und am engen sachlichen Zusammenhang mit der geplanten Novellierung des RJWG. Die SPD stand dabei vor dem Dilemma, daß sie einerseits die Annäherung an die katholische Wählerschaft suchte und laut Umfragen bis Ende 1960 auch zunehmend fand ${ }^{310}$, andererseits aber ihre starke Position vor allem in den städtischen Kommunen nicht gefährden wollte. Für diese erfolg-

$303 \mathrm{Vgl}$. Wehlitz, Rangfolge, S. $2 \mathrm{ff}$.

304 Ebenda, S. 5; ferner Wehlitz an Gottschick, 5.12.1960, BAK, B 106/9687.

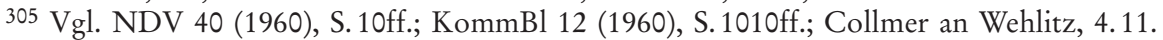
1960, ADW, HGSt, SP-S XXV 1: 400-1/1; Gottschick an Wehlitz, 9.12.1960, BAK, B 106/9687.

306 Vgl. die Tonband-Protokolle der Beiträge von Ohl u.a., Anlage zu Muthesius an Münchmeyer, 21.11.1960, ADW, HGSt, SP-S XXXIX 1b: 1-1/1; Collmer an Nopitsch, ADW, HGSt, SP-S XXV 1: 420-1/1; Collmer an Ranke, 14.11.1960, ADW, HGSt, SP-S XXV 1: 480-1/2.

307 Vgl. Hong, Welfare, S. $189 \mathrm{ff}$.

308 Vgl. Vorschläge des DV zum Entwurf eines Bundessozialhilfegesetzes o.D., PA, Gesetzesmaterialien III/349 A3; Niederschrift über die Sitzung des DV-Vorstands am 26.1. 1961, LAB, B Rep. 142-9, 1261.

309 Muthesius auf der Sitzung des Bundestagsausschusses für Kommunalpolitik und öffentliche Fürsorge am 25.1.1961, Kurzprotokoll, PA, Gesetzesmaterialien III/349 A2; Niederschrift über die Sitzung des DV-Vorstands am 26.1.1961, LAB, B Rep. 142-9, 1261; ähnlich auch Gerhard Scheffler, Bemerkungen, S. 64. Über ein Zustandekommen dieser Religionsgespräche ist nichts bekannt.

310 Vgl. Schwarz, Die Âra Adenauer 1957-1963, S. 216; Brehm, SPD, S. 119. 
reiche Kommunalpolitik stand vor allem Willy Brandt, der nicht nur im August 1960 offiziell zum Kanzlerkandidaten der SPD nominiert worden, sondern bereits seit 1959 auch Präsident des DST war. ${ }^{311}$ Auf ihrem Parteitag Ende November 1960 positionierte sich die SPD in dieser Frage ganz eindeutig: Auf Antrag Könens wurde dort eine Entschließung gegen die in den Wohlfahrtsgesetzen vorgesehenen Regelungen zur freien Wohlfahrtspflege an die Bundestagsfraktion überwiesen. ${ }^{312}$ Und auf der Kommunalpolitischen Konferenz der SPD Mitte Januar 1961 bezeichnete Hamburgs Erster Bürgermeister Nevermann die Gesetzentwürfe zur Sozial- bzw. Jugendhilfe als „Anschläge der Bundesregierung auf die kommunale Selbstverwaltung“ und die geplanten Subsidiaritätsregelungen als „staatspolitisch verderblich“; die Städte und Gemeinden, selbst primär zur Verwirklichung des Allgemeinwohls berufen, würden sich gegen den Versuch wehren, „ihnen in der Sozial- und Jugendarbeit privilegierte Partner aufzuzwingen“. $313 \mathrm{Im}$ Zweifelsfalle also wog die Behauptung politischer und gesellschaftlicher Machtpositionen in den Kommunen schwerer als das Bemühen um katholische Wählerstimmen. ${ }^{314}$

Bei der Union verlief die Entwicklung umgekehrt: Besorgt über die mögliche Abwanderung katholischer Wählerschichten und nach dem Fernsehstreit um ein besseres Verhältnis zur katholischen Kirche bemüht, wuchs hier die Bereitschaft, deren Wünschen politisch entgegenzukommen, auch auf Kosten christdemokratischer Landkreisvertreter. ${ }^{315}$ Allerdings war vor allem Adenauer peinlich darauf bedacht, nicht neue konfessionelle Gräben aufzureißen und den für die Union fatalen Eindruck zu erwecken, hier handele es sich um „katholische“ Politik. ${ }^{316} \mathrm{Be}$ reits auf dem CDU-Bundesparteitag Ende April 1960 hatte Heinrich Krone den Liberalismus-Vorwurf zurückgewiesen und eine angemessene Grenzziehung zwischen Individuum, Staat und Gesellschaft gefordert; ohne auf die geplanten Wohlfahrtsgesetze dabei ausdrücklich einzugehen, erklärte er, ähnlich wie Arbeitsmini-

311 Vgl. Schwarz, Die Ära Adenauer 1957-1963, S. $192 \mathrm{ff}$.

312 In der Entschließung hieß es u.a., der BSHG-Entwurf „macht die Gemeinden und Kreise lediglich zu Kostenträgern und gibt der freien Wohlfahrtspflege einen Öffentlichkeitscharakter, der ihr nicht zukommt und auch ihrem Wesen nicht entspricht“. Diese werde vielmehr „zum subventionierten Erfüllungsgehilfen für gesetzlich festgelegte Maßnahmen“; in: Protokoll der Verhandlungen, S. 736, auch S. 632f.

313 Frankfurter Allgemeine Zeitung, 12.1.1961; ähnlich der Tenor bereits auf der Kommunalpolitischen Bundeskonferenz der SPD am 24./25.6.1960 in Mülheim/Ruhr; vgl. KommBl 12 (1960), S. 554f.

$314 \mathrm{Vgl}$. Brehm, SPD, S.115ff. Bemerkenswerterweise war der DGB in seiner offiziellen Stellungnahme für den Bundestagsausschuß vom 4.5.1960 auf die $\$ \mathbb{S} 3,8$ und 10 überhaupt nicht eingegangen und hatte für $\ 86$ sogar eine Muß-Verpflichtung für die kommunalen Träger zur Gewährleistung ausreichender Einrichtungen gefordert, PA, Gesetzesmaterialien III/349 A3.

315 Ein Mann wie Heinrich Krone wandte sich dabei aber entschieden gegen eine Haltung, die kirchliche bzw. klerikale Forderungen unmittelbar in politische Entscheidung ummünzen wollte, wie er sie etwa bei Politikern wie Wuermeling und Süsterhenn, aber auch bei Helene Weber vermutete; vgl. Protokoll der Sitzung des CDU-Bundesvorstands am 23. 8.1960, in: Buchstab, Adenauer, S. 774.

316 Vgl. Sitzung des engeren CDU-Parteivorstands am 6.7.1960, in: Buchstab, Adenauer, S.713; allgemein Bösch, Adenauer-CDU, S. 324f.; Schwarz, Adenauer, Bd. 2, S. 606ff. 
ster Blank, der Staat dürfe „nicht in Gebiete übergreifen, die Sache der Eigenständigkeit der Person, der Kirchen, natürlicher wie kultureller und sozialer Gliederungen sind“. 317 Die keineswegs automatisch linientreuen christdemokratischen Kommunalfunktionäre ${ }^{318}$ wurden in der KPV-Zeitschrift über Fälle von Benachteiligung konfessioneller Träger durch sozialdemokratische Stadträte und Senatoren unterrichtet ${ }^{319}$ und plädierten auf ihrer Bundesversammlung im September 1960 im Beisein des Kanzlers und des Innenministers nach einem Referat Maria Niggemeyers klar für einen Vorrang der freien Verbände im BSHG-Entwurf, zumal durch die Eigenmittel und den hohen Anteil ehrenamtlicher Arbeit bei der freien Wohlfahrtspflege „eine erhebliche finanzielle Entlastung des Gemeindeetats" bewirkt werde. ${ }^{320}$ Vor allem aber wollte die Unionsführung noch einige Gesetzesvorhaben „ausgeprägt weltanschaulichen Charakters“321 in der laufenden Legislaturperiode durchsetzen und damit auch von der Vertretung der katholischen Laien offiziell erhobenen Wünschen entgegenkommen ${ }^{322}$; dazu gehörten die Erschwernis der Ehescheidung gegen den Willen des schuldlosen Teils, der Einstieg in das Kindergeld für das zweite Kind und - gegen den heftigen Widerstand der Industrie - die Ausweitung der Sonntagsruhe in der Eisen- und Stahlindustrie sowie eben das Sozialhilfegesetz und die Reform des RJWG. ${ }^{323}$

Diese Reform war mittlerweile zur Novelle geschrumpft: Ausschlaggebend für den Rückzug des Familienministers waren einerseits die heftigen Proteste insbesondere der CDU-regierten Länder, die die Einbeziehung der Jugendpflege als Eingriff in die eigene Kulturhoheit ebenso wie organisatorische und finanzielle Vorgaben ablehnten, nicht zuletzt aber die Kosten des erheblich erweiterten Aufgabenkatalogs der geplanten Jugendhilfe fürchteten. ${ }^{324}$ Andererseits gab es aber auch massive Einwände von seiten der Nachbarressorts: Bundesinnen- und Bundesfinanzministerium fällten ein vernichtendes Urteil auch über den dritten

317 Heinrich Krone, „Der Mensch in Familie, Staat und Gesellschaft“, in: Christlich Demokratische Union Deutschlands, 9. Bundesparteitag, S. 98-110, hier S. 103; Blank, ebenda, S.129, erklärte: „Persönliches und, folgend, gesellschaftliches Handeln aber haben vor dem staatlichen Eingriff unbedingten Vorrang."

318 Vgl. Niederschrift über die Sitzung des Wohlfahrtsausschusses der KPV der CDU am 21.12.1959, ACDP, KPV der CDU, IV-002-043/4.

319 Vgl. KommBl 12 (1960), S. 875.

320 Vgl. ebenda, S. 850 ff. (Zitat S. 904).

321 Schwarz, Die Ära Adenauer 1957-1963, S. 165.

322 Vgl. etwa Hinweise bei Krone, Tagebücher, Bd.1, S. 452, Eintrag vom 14.10.1960, über entsprechende Äußerungen Adenauers vor katholischen Verbandsvertretern am 13.10. 1960; ferner die sog. „Hildesheimer Erklärung“ des Zentralkomitees der Katholiken vom 23.11.1960, in: Herder-Korrespondenz 15 (1960/61), S.147-149, bes. 148f.; dazu auch Großmann, Kirche, S. $340 \mathrm{ff}$.

323 Vgl. Schwarz, Adenauer, Bd.2, S.608f. Zum Familienrechtsänderungsgesetz vom 11.8. 1961 sowie zum Kindergeldkassengesetz vom 18.7.1961 vgl. Rölli-Alkemper, Familie, S.513ff., 594ff.; Großmann, Kirche, S. 429f., 436f.; zur Verordnung zur Sonntagsruhe auch die Eintragungen Krones vom 26.10.1960, 7.11.1960, 8.1.1961 und 1.5.1961 über Verhandlungen mit Vertretern der Industrie und der katholischen Kirche, in: Krone, Tagebücher, Bd. 1, S. 454, 456, 466, 487.

324 Vgl. Hasenclever, Jugendhilfe, S. 199f.; Darius, Stellungnahme, S. 72; dagegen argumentierend Rothe, Jugendpflege. 
Vorentwurf, der nach wie vor zahlreiche formale Mängel aufweise, sich von anderen Rechtsgebieten, insbesondere dem BSHG-Entwurf, entgegen getroffener Abmachungen nur unklar abgrenze, in der Subsidiaritätsfrage verfassungsrechtlich höchst bedenklich und - wie das Finanzministerium ergänzte - auch nicht finanzierbar sei, zumal die vorgesehene Bundesbeteiligung mit der derzeitigen Finanzverfassung nicht zu vereinbaren sei; das Bundesarbeitsministerium opponierte vor allem gegen die vorgesehene Ausbildungshilfe, da es im März einen eigenen Entwurf über Berufsausbildungsbeihilfen auf den Weg gebracht hatte. ${ }^{325}$

Angesichts dieser heftigen Widerstände war die Verabschiedung eines umfassenden Reformgesetzes zur Jugendhilfe in der laufenden Legislaturperiode kaum mehr realistisch. ${ }^{326}$ Statt dessen beschloß das Bundeskabinett am 5. Oktober 1960 den im Familienministerium schließlich auf eine bloße Novelle des RJWG reduzierten Entwurf, der noch bis zum Sommer verabschiedet werden könnte. ${ }^{327} \mathrm{Ma}$ teriellrechtlich brachte die Novelle nur wenige, dem allgemeinen fachlichen Konsens entsprechende Neuerungen und klammerte die Ausbildungshilfen nun ganz aus. ${ }^{328}$ Auf organisatorischem Gebiet aber barg der Entwurf auch weiter „kulturpolitischen Sprengstoff“ “329. Sein erklärtes Hauptziel nämlich wollte der streitbare und zum Leidwesen seines ebenfalls überzeugt katholischen Fraktionsvorsitzenden politisch wenig kompromißbereite Familienminister ${ }^{330}$ nicht aufgeben: den weitgehenden - und in diesem Ausmaß auch von Bundesinnenminister Schröder nicht gestützten ${ }^{331}$ - Vorrang der konfessionellen Jugendhilfe gegenüber den

325 Vgl. BMI an BMFuJ, 25.5.1960; Vermerk Referat V 1 vom 10.6.1960; BMF an BMFuJ, 3.7.1960, Abschrift, BAK, B 106/20099.

$326 \mathrm{Vgl}$. BldW 107 (1960), S. 233.

327 Vgl. Kabinettsprotokolle 1960, S.346f.

328 Vgl. Entwurf eines Gesetzes zur Änderung und Ergänzung des Reichsjugendwohlfahrtsgesetzes, BT, 3. Wp. 1957, Anlagen, Bd.71, Drs. 2226. Vorgesehen war u.a.: Erhöhung des Schutzalters von Pflegekindern auf 16 Jahre, Ausbau der Heimaufsicht, Abschaffung der Anstaltsvormundschaft, Ausbau der Freiwilligen Erziehungshilfe, Erweiterung des Empfängerkreises erzieherischer Hilfen im Einzelfall durch Übernahme der Einkommensgrenzen aus dem BSHG-Entwurf. Im Interesse der Länder wurde auf den umfassenden, auch Aufgaben der Jugendpflege einbeziehenden Aufgabenkatalog des Jugendamtes verzichtet und die Regelung dieser Frage in einer Rechtsverordnung vorgesehen; vgl. BldW 107 (1960), S.337f.; auch Rothe, Neuordnung des Jugendwohlfahrtsrechts; zur Kritik siehe Neues Beginnen 1960, S. 173.

329 So die Bundestagsabgeordnete Marta Schanzenbach (SPD) vor dem DV-Hauptausschuß am 27./28. Januar 1961; NDV 41 (1961), S. 83.

330 Vgl. Krone, Tagebücher, Bd.1, Tagebuch-Eintrag vom 11.3.1960, S. 410f., über ein Gespräch mit dem Münsteraner Weihbischof Tenhumberg: „Wuermelings Radikalismus wird in seiner Gefährlichkeit erkannt. Daß Wuermeling grundsätzlich denkt und grundsätzlich gehandelt wissen will, wer widerspräche dem; doch übersieht er, daß wir heute in Deutschland ein religiös und weltanschaulich gespaltenes Volk sind und nicht alles nach unserem Denken aufbauen können, und weiter, daß es auch eine falsche Grundsätzlichkeit gibt, die dem Politiker den Weg verantwortungsbewußten Handelns sperrt.“; Eintrag vom 19.5.1961 S.498: „Es sind nicht alles Christen, die uns wählen. [...] Diese , liberalen' Wähler dürfen wir vor der Wahl nicht vor den Kopf stoßen. Wuermeling und einige andere Rigoristen sehen das nicht."

331 Schröder hatte sich bei der Abstimmung zu diesem Punkt im Kabinett der Stimme enthalten; vgl. Kabinettsprotokolle 1960, S. 347. 
kommunalen Trägern. ${ }^{332}$ War dieser Wunsch im sensiblen Erziehungsbereich ohnehin ideologisch noch brisanter als bei der Sozialhilfe, so kam hier persönliche Betroffenheit der Kontrahenten noch ungleich stärker zum Tragen: Der Streit um Recht und - vor allem - Kompetenz der öffentlichen Jugendfürsorge zur wertgebundenen Erziehung förderte die Emotionalisierung der Debatte und nicht die Kompromißbereitschaft der Beteiligten, fühlte sich doch eine Bundestagsabgeordnete wie etwa Marta Schanzenbach (SPD) als Jugendfürsorgerin auch persönlich in ihrer Berufsehre angegriffen. ${ }^{333}$

Im Bundesrat waren die Konstellationen ähnlich wie beim BSHG: Der Innenausschuß empfahl, die vorgesehenen Regelungen zur Stärkung des Elternrechts, die "Grundrichtung der Erziehung" - nicht zuletzt im Interesse weltanschaulicher Träger - zu bestimmen $(\mathbb{S} 2 \mathrm{a})^{334}$, ebenso zu streichen wie die Verpflichtung der öffentlichen Träger, die freien Verbände und deren Einrichtungen finanziell zu fördern $(\mathbb{4} 4$ Abs. 3-5 und $\ 4 a) .335$ Doch im Plenum am 28. Oktober wurde die von Niedersachsen eingebrachte Empfehlung, die Gesetzesmaterie vorerst nicht weiterzuverfolgen, von der Mehrheit der unionsgeführten Länder abgelehnt und der Entwurf im ersten Durchgang ohne Änderung in der Subsidiaritätsfrage verabschiedet. 336

Bei der ersten Lesung im Bundestag am 9. Dezember 1960 kam es zu heftigen Auseinandersetzungen zwischen Wuermeling und den Vertretern der SPD. Während sich Wuermeling und der zuständige Unionsvertreter Emil Kemmer (CSU) in der Subsidiaritätsfrage auf entsprechende Intentionen der Gesetzgeber von 1922 und 1953 beriefen und der Opposition Obstruktion attestierten, warf Irma Keilhack (SPD) dem Minister vor, nur um diese Bestimmungen zu retten, habe er alle übrigen Neuerungen fallengelassen und damit die jahrelangen Reformarbeiten auch seines eigenen Hauses für eine grundlegende Neugestaltung der Jugendhilfe

332 Vgl. Wuermeling im Bundestag am 9.12.1960, BT, 3. Wp. 1957, Sten. Ber., Bd. 47, S. 7724f.

333 Vgl. die Beiträge auf der Tagung des DV-Hauptausschusses am 27./28.1.1961, NDV 41 (1961), S. 69, bes. 83ff.; ferner Oel, Jugendhilferecht; ders., Neuordnung des Jugendhilferechts; Rothe, Neuordnung des Jugendhilferechts; die Antwort Oels in: Der Städtetag 13 (1960), S. 221f.; Soziale Arbeit 9 (1960), S. 382; Hasenclever, Reform.

334 Vgl. Art. I des Regierungsentwurfs, BT, 3. Wp. 1957, Anlagen, Bd. 71, Drs. 2226.

335 Vgl. Berichterstatter Goppel (Bayern) auf der Sitzung des Bundesrates am 28.10.1960, BR 1960 Sten. Ber., S. $499 \mathrm{ff}$ \4 Abs. 3 Satz 2 lautete: „Soweit geeignete Einrichtungen und Veranstaltungen der Träger der freien Jugendhilfe vorhanden sind, erweitert oder geschaffen werden, ist von eigenen Einrichtungen und Veranstaltungen des Jugendamts abzusehen." \4a bestimmte: „Einrichtungen und Veranstaltungen der Träger der freien Jugendhilfe sind unter Berücksichtigung der Eigenleistung nach den Grundsätzen zu fördern, die für die Finanzierung gleichartiger Einrichtungen und Veranstaltungen der Träger der öffentlichen Jugendhilfe gelten."

336 Vgl. Sitzung des Bundesrates am 28.10.1960, BR 1960 Sten. Ber., S. 503ff.; Stellungnahme des Bundesrates zum Regierungsentwurf, S.36, BT, 3. Wp. 1957, Anlagen, Bd.71, Drs. 2226. Der in dieser Frage nach wie vor lavierende Kiesinger begründete sein Votum allerdings damit, daß sich die baden-württembergische Landesregierung wegen der Kürze der Zeit noch keine abschließende Meinung habe bilden können und daher nur die unveränderte Weiterleitung des Regierungsentwurfs an den Bundestag empfehle, vgl. ebenda, S.502. In seiner Regierungserklärung am 7.7.1960 hatte Kiesinger zuvor den Verbänden der freien Wohlfahrtspflege „weitgehende staatliche Unterstützung“ zugesichert; vgl. BldW 107 (1960), S. 233. 
mißachtet. ${ }^{337}$ Nach einer teilweise „etwas tumultuarischen“338 Debatte wurde schließlich der Antrag der SPD- und FDP-Fraktionen, den Entwurf wegen der Subsidiaritätsfrage mitberatend an den Rechtsausschuß zu überweisen, von der Regierungsmehrheit abgelehnt. ${ }^{339}$

In den Beratungen des federführenden Bundestagsausschusses für Familienund Jugendfragen seit Mitte Januar 1961 blieben die unterschiedlichen Auffassungen ebenso bestehen wie auf einer Tagung des DV-Hauptausschusses Ende des Monats. ${ }^{340}$ Neben den inhaltlichen Parallelen zu den Beratungen über den BSHG-Entwurf gab es auch personelle Querverbindungen: So war der kommunalpolitische Ausschuß nicht nur mitberatend auch für die RJWG-Novelle zuständig, sondern einige seiner Mitglieder, darunter Maria Niggemeyer, gehörten selbst auch dem Jugendausschuß an. ${ }^{341}$ Nachdem sozialdemokratische Mitglieder des Jugendausschusses dazu aufgefordert hatten, Material über tatsächliche Benachteiligungen freier durch öffentliche Träger zusammenstellen zu lassen ${ }^{342}$, richtete das Familienministerium Mitte Februar eine entsprechende Bitte an die freien Verbände. ${ }^{343}$ Wie möglicherweise zu erwarten, wurde in den Rückmeldungen etwa bei der Diakonie sowohl von Fällen solcher Benachteiligung, ebenso aber von Beispielen gelungener Zusammenarbeit berichtet ${ }^{344}$, die Frage blieb damit auch weiterhin in erster Linie „politisch“ $\mathrm{zu}$ entscheiden. ${ }^{345}$

Aus Sicht der Unionsführung war es hier wie bei dem BSHG und den anderen „weltanschaulichen“ Gesetzen für die Bundestagswahl von entscheidender Bedeutung, daß diese auch von evangelischer Seite unterstützt wurden. ${ }^{346}$ Während aber die offiziellen katholischen Vertreter auch die einschlägigen Bestimmungen der RJWG-Novelle guthießen ${ }^{347}$, waren auf evangelischer Seite die Stimmen

337 Vgl. Bundestagssitzung am 9.12.1960, BT, 3.Wp. 1957, Sten. Ber., Bd.47, S.7724f., $7728 \mathrm{ff} ., 7739$.

338 NDV 41 (1961), S. 74.

339 Vgl. Bundestagssitzung am 9. 12.1960, BT, 3. Wp. 1957, Sten. Ber., Bd. 47, S. 7744.

340 Die Sitzungsprotokolle des Ausschusses für Familien- und Jugendfragen sind veröffentlicht in: Materialien, S. 203ff.; zur Sitzung des DV-Hauptausschusses am 27./28.1.1961 siehe NDV 41 (1960), S. $69 \mathrm{ff}$.

341 Neben Niggemeyer Emmi Welter (CDU), Helene Wessel und Kurt Schröder (SPD) sowie Kurt Spitzmüller (FDP).

${ }^{342} \mathrm{Vgl}$. Kurzprotokoll der gemeinsamen Sitzung des Ausschusses für Familien- und Jugendfragen und des Ausschusses für Kommunalpolitik und öffentliche Fürsorge am 11.1.1961, in: Materialien, S.208f.

343 Vgl. BMFuJ an Mordhorst, 16.2.1961; Rundschreiben der Hauptgeschäftsstelle von Innerer Mission/Hilfswerk an die Landes- und Fachverbände etc., 24.2.1961; Suhr an BMFuJ, 10.3.1961, ADW, HGSt, SP-S XXXIX 1b: 1-1/1. Vgl. ferner die Abg. Keilhack (SPD) auf der Sitzung des Bundestages am 28.6.1961, BT, 3. Wp. 1957, Sten. Ber., Bd. 49, S. $9505 f$.

$344 \mathrm{Vgl}$. die Antworten aus den Landesverbänden der Inneren Mission in: ADW, HGSt, SP-S XXXIX 1b:1-1/1.

345 Vgl. Frey, Gedanken, S. 1069.

346 Vgl. Krone, Tagebücher, Bd.1, Eintrag vom 7.1.1961, S.466; für die RJWG-Novelle und die Eherechtsänderung Eintrag vom 25.6.1961 [offensichtlich falsche Datierung, die beiden Gesetze wurden erst am 28.6. verabschiedet], S. $510 f$.

347 Vgl. die Stellungnahme des DCV-Jugendreferenten Schmidle vor den beiden Bundestagsausschüssen am 12.1.1961, Kurzprotokoll, in: Materialien, S. 219ff.; Frey, Gedanken. 
weiterhin sehr viel unterschiedlicher: Niedersächsische Kirchen- bzw. Diakonievertreter äußerten sich teilweise gegenüber SPD-Vertretern kritisch zu den ihrer Ansicht nach rein dem katholischen Subsidiaritätsprinzip verpflichteten Entwürfen. ${ }^{348}$ Währenddessen hatten sich die zuständigen Gremien der Diakonie und deren Sachverständiger im Bundestagsausschuß, hatte sich vor allem auch Bischof Kunst nach entsprechendem Vortrag im Rat der EKD eindeutig für die RJWGNovelle ausgesprochen. ${ }^{349}$ Collmer unterstützte nach den Diskussionen im DVHauptausschuß im November 1960350 noch sehr viel eindeutiger die im BSHG vorgesehenen Regelungen und teilte die Befürchtungen des aufgeschreckten Gottschick, daß „die SPD mit ihrem Einvernehmen auf der evangelischen Seite operieren würde" ". ${ }^{351}$ Hinzu kam, daß gerade auch wegen des Konnexes mit der Jugendhilfe die FDP, sonst der Neigung zur Ausweitung kommunaler oder staatlicher Aufgaben eher unverdächtig, mit der SPD in der Subsidiaritätsfrage wie seinerzeit in den Auseinandersetzungen um die Konfessionsschule zu einer „weltanschaulichen und grundsätzlichen Koalition" 352 fand und versuchte, genau diese Gesetze als spezifisch katholische zu etikettieren. 353

348 Vgl. Evangelischer Pressedienst (epd) vom 2.3.1961 (Abschrift); Vermerk Heun vom 17.4.1961, ADW, HGSt, SP-S XXV 1: 401-1/1; sowie Äußerungen des Hannoveraner Stadtkämmerers und stellvertretenden Mitglieds der Generalsynode der Vereinigten Evangelisch-Lutherischen Kirche Deutschlands Heinke, Freiheit.

349 Vgl. allgemein die Darstellung der Hauptgeschäftsstelle „Die Mitwirkung der Hauptgeschäftsstelle Innere Mission und Hilfswerk bei der Reform des Jugendwohlfahrtsrechtes“, o.D. Anlage zu Rundschreiben der Hauptgeschäftsstelle vom 19.10.1961, ADW, HGSt, SP-S XXV 1: 463-1/1; Pastor Georg Suhr von der Hauptgeschäftsstelle vor den Bundestagsausschüssen am 12.1.1961, in: Materialien, S.212f.; Kunst an Collmer, 28.2. 1961, ADW, HGSt, SP-S XXV1: 422-1/1; Vermerke Collmer vom 17. und 19.4.1961, ADW, HGSt, SP-S XXV 1: 401-1/1. Zu den unterschiedlichen Auffassungen in der evangelischen Kirche Matthes, Konzeptionen, S. 92ff., bes. $103 \mathrm{f}$.

350 In einem Brief an Antonie Nopitsch, 7.11.1960, klagte Collmer: „Die von den kommunalen Vertretern [auf der Hauptausschuß-Sitzung] vorgebrachten Argumente waren ja so niveaulos, wie sie selten in dieser Plumpheit und Unwahrhaftigkeit vorgetragen wurden.", ADW, HGSt, SP-S XXV 1: 420-1/1.

351 Collmer an Mordhorst, 5. 4.1961, ADW, HGSt 2486. Und zu Otto Ohl: „Meine Bedenken [...] bestanden vor allem in der Frage nach einer praktikablen Handhabung. Aber die von den Kommunen überhaupt gegen die Rechtsstellung der Verbände geltend gemachten Bestimmungen haben mich immer mehr erkennen lassen, dass sie vor allem gegen eine Schmälerung ihrer Kompetenzen angehen.", Collmer an Ohl, 4.3.1961, ADW, HGSt, SP-S XXV 1: 427-1/1. Gottschicks Befürchtungen bezogen sich auf ein Gespräch zwischen SPD-Bundestagsabgeordneten und Vertretern der evangelischen Kirche Ende Februar 1961, bei dem u.a. der evangelische Theologe und Jugendhilfefachmann Karl Janssen in Anwesenheit Collmers über das Subsidiaritätsprinzip referierte; vgl. Schellenberg an die Mitglieder der Bundestagsfraktion der SPD, 17.2.1961, AdsD, SPD-BTF 3. Wp., 135; Evangelischer Pressedienst (epd) vom 2.3.1961 (Abschrift), ADW, HGSt, SP-S XXV 1: 401-1/1.

352 So Rainer Barzel (CDU) bei der zweiten Lesung des BSHG im Bundestag am 3.5.1961, BT, 3. Wp. 1957, Sten. Ber., Bd. 49, S. 9038.

353 Unter Anspielung auf die zeitgenössische katholische Soziallehre sah der FDP-Pressedienst das BSHG etwa als „Wegmarke zum Ständestaat“; vgl. Evangelischer Pressedienst (epd) vom 12.5.1961, ADW, HGSt, SP-S XXV 1: 480-1/2. 
In dieser Atmosphäre zunehmender Polarisierung beriet der Ausschuß für Kommunalpolitik und öffentliche Fürsorge am 13./14. April 1961 in Berlin abschließend die einschlägigen Paragraphen des BSHG-Entwurfs. An den Beratungen nahmen von der Union elf Abgeordnete teil, von der SPD acht und der FDP zwei, die Abstimmungsverhältnisse waren also denkbar knapp. ${ }^{354}$ Am 13. April waren ungewöhnlich viele Ländervertreter zur Ausschußsitzung gekommen, darunter Senatsdirektor Wehlitz und Niedersachsens Staatssekretär Auerbach. Dieser wohl entschiedenste Gegner der geplanten Subsidiaritätsregelungen wollte das verfassungsmäßig garantierte, aber eher selten genutzte Anhörungsrecht für Bundesratsmitglieder in den Bundestagsausschüssen nutzen, um bei letzter Gelegenheit noch das Ruder herumzureißen. ${ }^{355}$ Bisher hatte der Ausschuß in der ersten Beratung nämlich immerhin - und auf seiten der Unionsabgeordneten möglicherweise auch in Verkennung der Bedeutung dieser Frage - den Vorrang der freien Verbände bei der Beratung in $\ 8$ Abs. 2 auf die „Beratung in sonstigen sozialen Angelegenheiten“ beschränkt, so daß bei der „Beratung in Fragen der Sozialhilfe“, also gerade zentralen Bereichen wie Pflege, Eingliederungshilfe, Gefährdetenhilfe etc., das Sozialamt nicht mehr zuerst auf die freien Verbände zu verweisen hatte. ${ }^{356}$ Außerdem hatte er die Verpflichtung zur Betreuung durch bekenntnisgleiche Geistliche in Einrichtungen etwas abgemildert ${ }^{357}$; für den Vorrang der freien Verbände im Einzelfall ( $\mathbb{S} 10$ Abs.4) hatte er in deren Interesse Geldleistungen eindeutig ausgenommen. ${ }^{358}$ In den übrigen strittigen Bestimmungen aber war es noch zu keiner Annäherung gekommen. In einem ausführlichen Referat konstatierte Auerbach eine „Aushöhlung des sozialpolitischen Wirkungsbereichs der Gemeinden“ und damit letztlich einen massiven staatspolitischen Funktionsverlust der Kommunen, wenn die vorgesehene „Funktionssperre“ bei der Sozialhilfe verwirklicht würde. ${ }^{359}$ Zudem - und das war stets der zweite Strang der Auerbachschen Argumentation - würde durch diese Subventionierung die Autonomie der Wohlfahrtsverbände empfindlich eingeschränkt. Er machte daher den Vorschlag, den Vorrang im Einzelfall deutlich zu begrenzen und bei den Einrichtungen zur alten Regelung des $\int 5$ RFV zurückzukehren. ${ }^{360}$ Der Bundestag könne diese Regelung ja nach zwei Jahren auf ihre Effektivität hin überprüfen. ${ }^{361}$

354 Vgl. Kurzprotokoll Kommunalpolitischer Ausschuß, 13.4.1961, PA, Gesetzesmaterialien III/349 A2.

355 Nach Art. 43 Abs. 2 GG haben Bundesregierung und Bundesrat sowie ihre Beauftragten Zutritt zu allen Ausschußsitzungen und müssen dort jederzeit gehört werden. In der Regel allerdings nehmen die Ländervertreter (oftmals vom Bundesrat entsandte Fachbeamte der Länder) nur beobachtend teil; vgl. Zeh, Ausschußsystem, S. $1098 f ., 1121$.

356 Vgl. Kurzprotokoll Kommunalpolitischer Ausschuß, 19.1., 9. 2.1961, PA, Gesetzesmaterialien III/349 A2.

357 Vgl. Kurzprotokoll Kommunalpolitischer Ausschuß, 6. 10.1960, ebenda, A1.

358 Vgl. Kurzprotokolle Kommunalpolitischer Ausschuß, 7. und 19. 10.1960, ebenda.

359 Referat Auerbach, Anlage zur Sitzung des Ausschusses für Kommunalpolitik und öffentliche Fürsorge [13.4.1961], ebenda, A4.

360 Vgl. ebenda sowie Kurzprotokoll Kommunalpolitischer Ausschuß, 13.4.1961, ebenda, A2; allgemein Auerbach, Miteinander.

361 Vgl. auch Auerbach an den DST-Referenten Lehmann-Grube, 26. 4.1961, LAB, B Rep. 142-9, 1285. 
Für die RJWG-Novelle lag nämlich mittlerweile ein Gutachten des renommierten Verfassungsrechtlers Arnold Köttgen vor, das der DST in Auftrag gegeben hatte und das die dort vorgesehenen Subsidiaritätsbestimmungen für nicht mit dem Grundgesetz vereinbar erklärte, woraufhin der Jugendausschuß nun doch den Rechtsausschuß um ein Gutachten gebeten hatte. ${ }^{362}$ Für das BSHG versicherten die anwesenden Beamten des Innen- und des Justizministeriums jedoch, daß die einschlägigen Paragraphen nach gründlicher Prüfung für verfassungskonform befunden worden seien. Als Abgeordnete der SPD und FDP daraufhin ebenfalls den Rechtsausschuß einschalten wollten, wurde das mit der einen Stimme Mehrheit der Union abgelehnt - weitere Verzögerungen sollten für das BSHG nicht mehr in Kauf genommen werden. ${ }^{363}$ So wurden die Subsidiaritätsregelungen nach zahlreichen Änderungsanträgen der SPD- und FDP-Abgeordneten nur mit der knappen Mehrheit der Unionsvertreter im Ausschuß angenommen. ${ }^{364} \mathrm{Um} \mathrm{zu}$ verhindern, daß auch kommerziellen Trägern ein Vorrang eingeräumt wurde, beschränkte der Ausschuß diesen auf „Einrichtungen der Verbände der freien Wohlfahrtspflege oder öffentlich-rechtlicher Träger“; bei letzterem hatten zwar alle Beteiligten primär an Einrichtungen etwa der Landesversicherungsanstalten gedacht, doch galten, wie man im Katholischen Büro besorgt vermerkte, auch die Kommunen oder kommunale Stiftungen als öffentlich-rechtliche Träger, und war damit der Vorrang der freien Verbände leicht zu unterlaufen. ${ }^{365}$ Mit Stimmen aus den Reihen der Opposition wurde außerdem der Vorrang der freien Wohlfahrtsverbände eindeutiger auf die Einzelfälle begrenzt, in denen die nötige Hilfe von diesen tatsächlich bereits „eingeleitet und gewährleistet“ war. ${ }^{366}$ Die bisher beschlossenen Änderungen zum Wahlrecht und zur Beratung behielt der Ausschuß einstimmig bei.

Alles in allem hatte damit der BSHG-Entwurf den Ausschuß für Kommunalpolitik und öffentliche Fürsorge ganz im Sinne der Bundesregierung passiert: Die meisten Verbesserungen - außer dem festen Pflegegeld - waren bereits vom Bundesrat empfohlen und von der Bundesregierung zustimmend bewertet worden, die Gefährdetenhilfe war im Gesetz geblieben, ebenso die organisatorischen Vorgaben und auch die Regelung der Kostenersatzpflicht - all dies im Einvernehmen mit der Opposition. Wünsche nach Leistungsreduzierungen und unverbindlicheren Regelungen von kommunaler Seite, insbesondere des DLT, hatte der Ausschuß nicht übernommen; das in der Phase der Referentenentwürfe vor allem

362 Vgl. Rechtsgutachten von Arnold Köttgen, Februar 1961, PA, Gesetzesmaterialien III/349 A4.

363 Vgl. auch zum Folgenden Kurzprotokolle Kommunalpolitischer Ausschuß, 13. und 14.4.1961, ebenda, A2.

364 Den Absätzen 1, 2 und 4 (entsprach ursprünglich Absatz 5) von $\ 10$ stimmten auch die Abgeordneten der SPD und der FDP zu; bei $\$ 10$ Abs. 3 hatte sich die Mehrheit der Oppositionsvertreter enthalten.

365 Vgl. auch Wissing an Krone, 29.4.1961, Anlage 2, ACDP, NL Krone, I-028-062/3.

$366 \int 10$ Abs. 5 sollte jetzt lauten: „Sind die erforderlichen Hilfemaßnahmen im Einzelfalle von der freien Wohlfahrtspflege eingeleitet und gewährleistet, sollen die Träger der Sozialhilfe von eigenen Maßnahmen absehen; dies gilt nicht für die Gewährung von Geldleistungen." Dieser Fassung stimmte der Ausschuß mit 14:3:3 Stimmen zu. 
durch die Länder und das Bundesfinanzministerium getragene Einflußpotential der kommunalen Spitzenverbände war bei den Beratungen des Bundestagsausschusses nur noch unerheblich. Der Wunsch nach einem modernen Sozialgesetz vor der Bundestagswahl sowie das generell in den Bundestagsausschüssen zu beobachtende Interesse der Abgeordneten der Regierungspartei, einen Regierungsentwurf möglichst unversehrt durch den Ausschuß zu bringen ${ }^{367}$, dominierte gegenüber dem Bestreben, kommunalpolitische Interessen, für die der Ausschuß ja auch zuständig war, zu berücksichtigen. Das galt vor allem für die Frage der Stellung der freien Wohlfahrtspflege. Denn hier bot selbst die Tatsache, daß ein ausgewiesener Kommunalfunktionär den Ausschuß leitete, keine Gewähr für die Berücksichtigung kommunaler Belange. Gerade in der Subsidiaritätsfrage erwies sich damit der Bundestagsausschuß tatsächlich „als ziemlich stumpfes Instrument der kommunalen Einflußnahme“.368

\section{Streit trotz prinzipieller Übereinstimmung: der Regierungsentwurf im Bundestagsplenum}

Knapp zwei Wochen nach dem Ende der Ausschußberatungen lag der im wesentlichen in der Sozialabteilung formulierte offizielle schriftliche Bericht des Ausschusses vor, in dem - parlamentarischem Usus gemäß - auch die Mindermeinung zur Subsidiaritätsfrage ausführlich dargelegt wurde. ${ }^{369}$ Die vom Ausschuß bzw. Bundesrat empfohlenen Leistungsverbesserungen gegenüber dem Regierungsentwurf würden einschließlich des festen Pflegegeldes jährliche Mehrkosten von insgesamt rund 70 Mio. DM verursachen; ein gutes Drittel dieser Mehrkosten (26,3 Mio. DM) entfiel - etwa im Rahmen des nicht pauschalierten Teils der Kriegsfolgenhilfe und der Tuberkulosehilfe - auf den Bund. ${ }^{370}$ Da der Haushaltsausschuß keine Einwände dagegen erhoben hatte 371 , wurde die zweite und dritte Lesung des BSHG-Entwurfs auf den nächstmöglichen Termin, den 3./4. Mai 1961, angesetzt. ${ }^{372}$

367 Vgl. Melzer, Vorbereitung, S. $1132 \mathrm{f}$.

368 Jaedicke u.a., Politik, S. 41.

369 Vgl. Schriftlicher Bericht des Ausschusses für Kommunalpolitik und öffentliche Fürsorge vom 25.4.1960, insbesondere S.3f., 10, BT, 3. Wp. 1957, Anlagen, Bd.74, Drs. 2673. Zur Abfassung durch die Sozialabteilung vgl. die Schreiben Gottschicks an Niggemeyer bzw. Könen vom 17.3. und 20.4.1961, BAK, B 106/20654.

Der mitberatende Gesundheitsausschuß hatte bereits im September 1960 dem Regierungsentwurf einschließlich der von der Regierung übernommenen Bundesratsempfehlungen zugestimmt; vgl. Kurzprotokoll der Sitzung des Ausschusses für Gesundheitswesen am 21.9.1960, PA, Gesetzesmaterialien III/349 A1.

370 Vgl. Kurzprotokoll der Sitzung des Haushaltsausschusses am 27. 4.1961, ebenda.

371 Vgl. Bericht des Haushaltsausschusses [...] über den Entwurf eines Bundessozialhilfegesetzes vom 27.4.1961, BT, 3. Wp. 1957, Anlagen, Bd. 74, Drs. 2707.

372 Laut $\int 80$ der Geschäftsordnung des Bundestages durfte die zweite Lesung frühestens zwei Tage nach Verteilung des Ausschußberichts als Bundestagsdrucksache stattfinden; vgl. Lechner-Hülshoff, Parlament, S. 200. 